\title{
CCL21/CCR7 interaction promotes cellular migration and invasion via modulation of the MEK/ERK1/2 signaling pathway and correlates with lymphatic metastatic spread and poor prognosis in urinary bladder cancer
}

\author{
YANG XIONG $^{1}$, FANG HUANG $^{1}$, XIAOZHOU LI $^{1}$, ZHI CHEN $^{1}$, \\ DEYUN FENG $^{2}$, HAIYING JIANG ${ }^{2}$, WEI CHEN ${ }^{2}$ and XIANGYANG ZHANG ${ }^{1}$
}

Departments of ${ }^{1}$ Urology, and ${ }^{2}$ Pathology, Xiangya Hospital, Central South University, Changsha, Hunan 410008, P.R. China

Received December 5, 2016; Accepted May 2, 2017

DOI: 10.3892/ijo.2017.4003

\begin{abstract}
Lymph node metastasis in patients with urinary bladder cancer (UBC) is always associated with poor prognosis and is the determinant for tumor staging and the development of treatment regimens; however, its underlying mechanisms remain to be studied. Immunohistochemical staining of tumor sections from 62 UBC patients was performed using CCR7, D2-40 and CD34 antibodies. We showed that increased CCR7 expression was significantly associated with positive lymph node status $(\mathrm{P}=0.008)$, pT3-T4 tumor stage $(\mathrm{P}=0.015)$, tumor grade $(\mathrm{P}=0.010)$ and worse overall survival $(\mathrm{OS}, \mathrm{P}<0.001)$ and that both CCR7 expression and lymph node metastasis were independent prognostic factors for $\mathrm{OS}(\mathrm{P}=0.031$ and $\mathrm{P}=0.001$, respectively) based on multivariate analysis. We found that there was a significant association between MLVD and lymph node status $(\mathrm{P}=0.006)$, but this relation was not observed for MVD. Furthermore, we showed that increased CCR7 expression correlated significantly with higher MLVD $(\mathrm{P}=0.014)$ and MVD $(\mathrm{P}=0.002)$. Wound-healing and Matrigel Transwell assays indicated that activation of CCR7 with CCL21 significantly enhanced the invasion and migration abilities of UM-UC-3 cells, and this enhanced effect was significantly abrogated by CCR7 knockdown using siRNA.
\end{abstract}

Correspondence to: Dr Xiangyang Zhang, Department of Urology, Xiangya Hospital, Central South University, 87 Xiangya Road, Changsha, Hunan 410008, P.R. China

E-mail: hsmwyzjs@foxmail.com

Abbreviations: MLVD, microlymphatic vessel density; MVD, microvessel density; CCL21, chemokine (C-C motif) ligand 21 CCR7, C-C chemokine receptor 7; ERK, extracellular signalregulated kinase; siRNA, small interfering RNA

Keywords: urinary bladder cancer, lymph node metastasis, CCR7, CCL21, migration, invasion, angiogenesis, lymphangiogenesis, prognosis
Western blot analysis revealed that the phospho-ERK1/2 level was markedly increased when UM-UC-3 cells were treated with CCL21 and significantly decreased when the CCR7 gene was silenced. MEK/ERK1/2 inhibition with PD98059 significantly suppressed the migration and invasion abilities of UM-UC-3 cells and also significantly abrogated the effects of CCL21/CCR7 on cell migration and invasion. Based on these results, we conclude that activation of the CCL21/CCR7 chemoaxis promotes lymph node metastasis of UBC in at least two ways. Firstly, although CCR7 is a promoting factor that induces both lymphangiogenesis and angiogenesis, it may promote lymph node metastasis through its lymphangiogenic effect rather than through its angiogenic effect. Secondly, the CCL21/CCR7 chemoaxis promotes the migration and invasion of UBC cells via the MEK/ERK1/2 signaling pathway rather than the PI3K/AKT pathway.

\section{Introduction}

Urinary bladder cancer (UBC), which is mainly accompanied by symptoms of intermittent hematuria and vesical irritability, is the ninth most common type of cancer worldwide (1) and the second most common cancer of the genitourinary tract (2), with an estimated 76,960 newly diagnosed cases and 16,390 deaths in the United States in 2016 (3). Cigarette smoking is the most important risk factor for this heterogeneous cancer; other risk factors include schistosoma haematobium, occupational exposure to benzidine, $\beta$-naphthylamine, dyes or leather and physical trauma to the uroepithelium from infection, instrumentation or the presence of calculi. With respect to histopathology, transitional cell carcinomas account for $>90 \%$ of all bladder cancers, whereas adenocarcinomas, squamous cell carcinomas (SCC) and undifferentiated bladder carcinomas constitute the remaining $10 \%$ of bladder cancers (4).

$\mathrm{UBC}$ displays the characteristic of frequent progression both at the time of diagnosis and after initial treatment. Such progression is the outcome of a tumorous natural history that includes the two closely related processes of invasion and metastasis. Tumor progression involves the migration of tumor cells and the invasion of other tissues and remains the 
most common cause of cancer-related deaths (5). Although non-muscle-invasive bladder cancer (NMIBC) accounts for $\sim 70 \%$ of UBCs at initial presentation (6) and carries a 5-year survival rate of $90 \%$ (7), NMIBC tumors recur at a rate of $50-70 \%$ and progress at a rate of $15 \%$ in recurrent UBC patients (8). When NMIBC progresses to muscle-invasive bladder cancer (MIBC), which may display the characteristics of metastatic malignant tumors and subsequently lead to death, the 5-year survival rate falls to $60 \%$ (7). Even worse, $\sim 50 \%$ of MIBC patients succumb to this disease despite optimal therapy (9), and $\sim 80 \%$ of UBC patients with positive lymph node metastases die within the first 5 years after initial confirmed diagnosis $(10,11)$. Tumor metastasis, which includes hematogenous and lymphatic metastasis, is one of the most critical aspects of tumor progression and contributes to $\sim 90 \%$ of cancer-associated deaths (12). Despite advances in surgical techniques and in adjuvant chemotherapies and immunotherapies resulting from recent extensive studies of treatment options for advanced UBC with or without metastatic disease, the 5-year survival rate for patients with metastatic UBC was $5 \%$ (13), and that of patients with lymph node metastasis was $<30 \%$ (14). Although conventional clinicopathological characteristics such as tumor grade and stage provide important prognostic information in UBC, they are of limited use in the prediction of tumor recurrence, progression, treatment response, and survival (15), partially due to the shortcomings of staging and grading subjectivity that can lead to high interobserver variability (16). Therefore, the investigation of novel molecular markers that are positively associated with tumor progression, metastasis and survival and determination of the molecular mechanisms of these markers in tumor progression are crucial for improving poor survival in UBC and developing a more exact prognosis-predictive and therapeutic strategy.

Various chemokines and their specific receptors have been shown to be involved in tumor progression, and some receptors have been particularly proposed as biomarkers for predicting survival, such as the CXCL12/CXCR7 axis in pancreatic (17), the CXCL12/CXCR4 axis in breast $(18,19)$ and oral SCC (20), the CCL5/CCR1 axis in prostate (21) and the CCL21/CCR7 axis in gastric cancer (22). Among these, the most important chemokine/receptor axes are CXCL12/CXCR4 and CCL21/CCR7, mainly because of their determinant role in regulating the directional migration and organ-selective metastasis of tumor cells. An early breast cancer study showed significantly elevated CXCR4 and CCR7 expression in breast cancer cell lines and in tissue samples from patients and from mice in an established breast cancer model compared with normal controls (18). Given the preferential expression of CXCL12 in lung, liver and bone marrow and of CCL21 in lymph nodes found in the present study, the authors concluded that the CXCL12/CXCR4 axis may be responsible for metastasis to lung, liver and bone marrow and that CCL21 may be responsible for metastasis to lymph nodes (18). Notably, these hypotheses were confirmed by the results of subsequent experiments in vivo.

In the present study, we were most interested in the expression profile of CCR7 and the significance of the CCL21/CCR7 axis in progression, metastasis and survival in human UBC. Therefore, in the present study, we have initially evaluated the expression of CCR7 by immunohistochemical staining and determined its correlation with clinicopathological characteristics in 62 closely screened UBC patients. In addition, we investigated the microlymphatic vessel density (MLVD) and the microvessel density (MVD) in this cohort and determined their associations with CCR7 expression and clinicopathological parameters. These data provide preliminary evidence for a significant role of CCR7 in tumor progression, angiogenesis, lymphangiogenesis, survival and prognosis in UBC. In addition, the invasion and migration abilities of UBC cell lines with or without the intervention of CCL21 treatment or CCR7 gene silencing were tested in vitro. To further elucidate the mechanisms through which the CCL21/CCR7 axis regulates tumor behavior, the activities of the AKT and ERK-1/2 signaling pathways were also analyzed.

\section{Materials and methods}

Cell lines and reagents. The human bladder cancer cell lines T24, 5637, UM-UC-3 and RT4, as well as the SV-40 immortalized human uroepithelial cell line SV-HUC-1, which was used as a normal control, were purchased from the Cell Bank of the Chinese Academy of Sciences (Shanghai, China). The cells were cultured in Dulbecco's modified Eagle's medium (DMEM; Gibco, Grand Island, NY, USA) (UM-UC-3), RPMI-1640 medium (T24, 5637 and RT4) and F12K medium (SV-HUC-1) supplemented with $10 \%$ fetal bovine serum (FBS; Gibco), 100 units $/ \mathrm{ml}$ penicillin, $100 \mu \mathrm{g} / \mathrm{ml}$ streptomycin and $2 \mathrm{mmol} / \mathrm{l}$ glutamine at $37^{\circ} \mathrm{C}$ in a humidified chamber supplemented with $5 \% \mathrm{CO}_{2}$. When the cells reached $80-90 \%$ confluency, they were treated with various concentrations of recombinant human CCL21 purchased from PeproTech (Rocky Hill, NJ, USA) or with specific concentrations of CCL21 for $48 \mathrm{~h}$ to analyze the effect of activation of the CCL21/CCR7 axis on the invasion and migration capacity of UBC cells and the expression of possible related signaling pathway biomarkers.

Streptavidin-peroxidase (SP) ready-to-use kits, diaminobenzidine $(\mathrm{DAB})$ tetrahydrochloride chromogenic reagent and mouse monoclonal antibody against CD34 were purchased from Beijing Zhongshan Golden Bridge Biotechnology (Beijing, China). Rabbit monoclonal antibody to CCR7, rabbit polyclonal antibody to total-ERK1/2 and rabbit monoclonal antibody to phospho-ERK1/2 were obtained from Abcam (Cambridge, MA, USA). Rabbit polyclonal antibody to AKT and rabbit polyclonal antibody to phospho-AKT were from ImmunoWay Biotechnology Inc., (Newark, DE, USA). Mouse monoclonal antibody to $\beta$-actin and horseradish peroxidase (HRP)-conjugated secondary antibodies were from Santa Cruz Biotechnology (Santa Cruz, CA, USA). Mouse monoclonal antibody to D2-40 was from Dako (Carpinteria, CA, USA). RIPA lysis buffer and the BCA protein assay kit were from Beyotime Institute of Biotechnology (Haimen, China). Sodium dodecyl sulfate polyacrylamide gel electrophoresis (SDS-PAGE) loading buffer was from Auragene Bioscience (Changsha, China). Lipofectamine 2000 was from Invitrogen (Carlsbad, CA, USA). Small interfering RNA (siRNA) oligonucleotides targeting the CCR7 gene and a control scrambled sequence siRNA were designed and synthesized by Shanghai GenePharma Co., Ltd. (Shanghai, China). PD98059 was obtained from Sigma-Aldrich (St. Louis, MO, USA). 
Patient population and tissue specimen collection. After obtaining approval from the Xiangya Hospital Institutional Review Board, the clinical and pathological data of consecutive UBC patients who underwent radical cystectomy with bilateral pelvic and iliac lymphadenectomy at the authors' institution between June 2006 and June 2011 were reviewed. We included only patients for whom sufficient tissue and valid follow-up data were available and from whom written informed consent was obtained before they were enrolled in the study. We also excluded patients who received neoadjuvant chemotherapy or radiotherapy and those who exhibited synchronous or metachronous cancer in other organs, which finally left 62 patients for the analysis.

Tissue specimens were immediately formalin-fixed after surgery and then embedded in paraffin for immunohistochemical analysis. Sections from each case were stained with hematoxylin and eosin and investigated by light microscopy to confirm histopathology. The pathological tumor stage and grade were assigned according to the 2009 UICC-TNM classification system and the 2004 WHO system, respectively. Eight additional samples of normal bladder tissues were also obtained from sites apparently distant from the tumors. All procedures were performed in accordance with the ethical principles set forth in the Declaration of Helsinki. We had no access to information that could be used to identify individual participants during or after data collection.

Immunohistochemical staining and evaluation. UBC tissue samples were fixed in $10 \%$ formalin, embedded in paraffin, and cut into $4-\mu \mathrm{m}$ slices. Immunohistochemical staining was performed on a single representative block from each case using the streptavidin-peroxidase method with an SP readyto-use kit according to the manufacturer's instructions. Tissue blocks with at least $1 \mathrm{~mm}$ of peripheral tissue surrounding the tumor mass were selected. The tissue blocks were deparaffinized by incubating them twice in xylenol for $10 \mathrm{~min}$ at room temperature, dehydrated in a graded ethanol series $(50,75$ and $100 \%$ ), incubated in $3 \%$ hydrogen peroxide for $30 \mathrm{~min}$ to block endogenous peroxidases, subjected to antigen retrieval in $10 \mathrm{mmol} / \mathrm{l}$ citric acid buffer ( $\mathrm{pH} \mathrm{6.0)}$ in a microwave oven for $10 \mathrm{~min}$ and allowed to cool at room temperature. Following three 5-min washes in phosphate-buffered saline (PBS), the sections were treated with normal goat serum for $10 \mathrm{~min}$ at room temperature to block non-specific antibody reactions. The sections were further incubated overnight at $4^{\circ} \mathrm{C}$ with the following diluted primary antibodies according to the manufacturer's instructions: rabbit monoclonal anti-CCR7 (1:200), mouse monoclonal anti-CD34 (1:200) and mouse monoclonal anti-D2-40 (1:50). The sections were then sequentially incubated with anti-goat polyvalent antibody for $10 \mathrm{~min}$ and with streptavidin-peroxidase for $10 \mathrm{~min}$ and subsequently visualized by incubation in $0.03 \%$ DAB tetrahydrochloride chromogenic reagent followed by counterstaining with hematoxylin. For negative controls, PBS was used as a substitute for the primary antibody. Human spleen tissues and normal lymph nodes were used as positive controls for CCR7 and D2-40 staining, respectively, as suggested by the manufacturer.

For each tissue section, immunohistochemical detection of CCR7 expression was evaluated independently by two pathologists who were blinded to the patients' clinicopatholog- ical data. Expression was evaluated using a semi-quantitative scoring system that depended on the percentage of positively stained tumor cells and the staining intensity. The percentage of positively stained cells was graded on a semi-quantitative 5-point scale as follows: 0 (none); 1 (1-10\%); 2 (11-50\%); 3 (51-75\%); and 4 (76-100\%). The immunostaining intensity was graded on a semi-quantitative 4-point scale as follows: 0 (none, equivalent to the negative control); 1 (weak, slightly darker than the negative control); 2 (moderate, equivalent to an intensity between that of scores 1 and 3); and 3 (intense, equivalent to or darker than the positive control). Then, the percentage of positively stained cells and the staining intensity score were multiplied to yield a final score ranging from 0 to 12. Borderline cases were re-evaluated by joint review and discussion or by consultation with a third investigator familiar with immunohistochemical evaluation of pathology.

Evaluation of MLVD and MVD. For evaluation of MLVD and MVD, tissue sections were stained with D2-40 (a monoclonal antibody containing 166 amino acids that recognizes a sialoglycoprotein expressed in lymphatic endothelial cells with high specificity and affinity and thus is widely used for labeling microlymphatic vessels) and CD34 (a highly glycosylated transmembrane glycoprotein that is expressed in vascular endothelial cells and thus is widely used for labeling microvessels) antibodies, respectively. MLVD and MVD were assessed by two independent pathologists who had no prior knowledge of the patient information according to the following steps: Firstly, areas with the most intense vascularization (hot spots) were selected under low-power magnification (x40 or x100); secondly, average MLVD/MVD was measured at high-power magnification (x200) in 3 randomized fields within the hot spots following agreement of the two pathologists. For each section, MLVD/MVD was defined as the average number of positively stained vessels per high-power field (HPF) in three HPFs within the selected hot spots. Hot spots within both the intratumoral area, which was defined as the area within the tumor mass, and peritumoral area, which was defined as the area within $1 \mathrm{~mm}$ of the tumor border, were analyzed. In addition to distinct stained vessels, single immunoreactive endothelial cells or clusters of immunoreactive endothelial cells (containing brown-colored particles due to the positive expression of CD34 or D2-40) that were clearly separated from the adjacent clusters or vessels, regardless of the presence of lumen, were also counted as one microvessel or as one microlymphatic vessel.

CCR7 gene silencing by siRNA. The target sequences of three siRNAs of CCR7 and one siRNA with a scrambled sequence, which served as a non-silencing control due to its random sequence that does not target any gene product, were as follows: CCR7 siRNA1 sense: 5'-GCGUCCUUCUCAUCAG CAAdTdT-3' and antisense: 5'-UUGCUGAUGAGAAGGA CGCdTdT-3'; CCR7 siRNA2 sense: 5'-GCUGGUCGUGUU GACCUAUdTdT-3' and antisense: 5'-AUAGGUCAACACGA CCAGCdTdT-3'; CCR7 siRNA3 sense: 5'-GAUGAGGUCA CGGACGAUUdTdT-3' and antisense: 5'-AAUCGUCCGUGA CCUCAUCdTdT-3'; scrambled siRNA sense: 5'-AGUUCAA CGACCAGUAGUCdTdT-3' and antisense: 5'-GACUACUGG UCGUUGAACUdTdT-3'. Cells in 6-well culture plates were 
transfected with siRNA using Lipofectamine 2000 transfection reagent according to the manufacturer's instruction, and the transfection efficiency was assessed by western blot assay. Cells that showed effective depletion of CCR7 were selected for use in cell migration assays, cell invasion assays and western blot analysis.

Protein extraction and western blot analysis. Cells were lysed in RIPA lysis buffer for $30 \mathrm{~min}$ at $4^{\circ} \mathrm{C}$ and centrifuged at $130,00 \mathrm{rpm}$ for $20 \mathrm{~min}$ at $4^{\circ} \mathrm{C}$; the protein concentration of the lysate was measured using the BCA protein assay kit. Protein samples were mixed with an equal amount of SDS-PAGE loading buffer and separated using 10\% SDS-PAGE. After electrophoresis, proteins were transferred to polyvinylidene fluoride membranes by semi-dry electrophoretic transfer. The membranes were blocked in 5\% skim milk and incubated with primary antibodies to CCR7 $(1: 5,000)$, phospho-ERK (1:500), total-ERK $(1: 2,000)$, phospho-AKT $(1: 2,000)$, and total-AKT $(1: 2,000)$ overnight at $4^{\circ} \mathrm{C}$. Monoclonal $\beta$-actin antibody (1:500) was used to provide a loading control. The membranes were washed five times in TBST and incubated with HRP-conjugated secondary antibodies. Immunoreactive bands were imaged with an EC3 300 Imaging System (UVP LLC, Upland, CA, USA), and the OD values corresponding to the image intensity were measured using Image-Pro Plus version 6.0 (IPP6.0; Media Cybernetics, Inc., Rockville, MD, USA) software.

Wound-healing assay. To assess the migration ability of human UBC cells, a wound-healing assay was performed. Cells were plated in 6-well culture dishes and incubated with DMEM containing $10 \%$ FBS with or without CCL21 treatment for $24 \mathrm{~h}$ at $37^{\circ} \mathrm{C}$ under $5 \% \mathrm{CO}_{2}$. When the cells had formed a confluent monolayer, a scratch was made with a fine pipette tip, forming a linear wound in the central area of the cell monolayer, and the detached cells were carefully removed using PBS. The wound area was photographed at the beginning of the experiment and at 24 and $48 \mathrm{~h}$ after wounding the cell monolayer. Cell migration was assessed by measuring the size of the wound gap in at least six fields. The wound-healing assay was performed in triplicate.

Matrigel invasion assay. To assess the invasion ability of human UBC cells, a Matrigel invasion assay was performed using a polycarbonate membrane Transwell chamber containing a filter $6.5 \mathrm{~mm}$ in diameter with $8-\mu \mathrm{m}$ pores (Corning Inc., Corning, NY, USA). The Transwell filter was precoated with basement membrane Matrigel (BD Biosciences, San Jose, CA, USA). Briefly, cells pretreated with or without CCL21 for $48 \mathrm{~h}$ were resuspended in serum-free DMEM medium, and $300 \mu \mathrm{l}$ of the cell suspension $\left(5 \times 10^{4}\right.$ cells) was added to the upper chamber of the device. DMEM containing 10\% FBS was added to the lower chamber as a chemoattractant. After incubation for $24 \mathrm{~h}$ at $37^{\circ} \mathrm{C}$ under $5 \% \mathrm{CO}_{2}$, non-invasive cells on the upper surface of the filter were removed completely and carefully using cotton swabs, and the lower surface of the filter was fixed in $4 \%$ formaldehyde and stained with $0.5 \%$ crystal violet for $20 \mathrm{~min}$. After washing the filter twice with PBS, the cells on the lower side of the filter were photographed using an inverted microscope (x100 magnification), and absorbance was measured at $570 \mathrm{~nm}$. The Matrigel invasion assay was performed in triplicate.

Statistical analysis. Data are presented as the mean \pm standard deviation (SD) of the values obtained in three independent experiments or as the median (minimum-maximum) for nonnormally distributed data. Qualitative variables such as sex, histological grade, tumor stage and lymph node involvement are presented as frequencies or percentages. Qualitative variables were analyzed using the Chi-square test or Fisher's exact test as appropriate. Quantitative variables were compared using the independent t-test or one-way analysis of variance (ANOVA) to compare differences in 2 or more groups, and the least significant difference (LSD) t-test, the Dunnett's t-test or the Student-Newman-Keuls (SNK) q-test, as appropriate, were used for post hoc subgroup analysis. Survival curves were calculated using the Kaplan-Meier method, and differences in the survival curves were examined using the log-rank test. Cox's proportional hazard regression model was used for multivariate analysis to assess the effect of tumor variables on the prognosis of UBC. Statistical analysis was performed using SPSS statistical software, version 19.0 (IBM, Armonk, NY, USA). The significance of differences was accepted at $\mathrm{P}<0.05$ (2-tailed).

\section{Results}

Correlation between CCR7 expression and clinicopathological parameters and prognosis in 62 UBC patients. The expression and distribution of CCR7 protein in UBC tissues of different grades and stages, including papillary urothelial neoplasm of low malignant potential (PUNLMP), low-grade urothelial carcinoma (LGPUC) and high-grade urothelial carcinoma (HGPUC), as well as stage T1 (tumor invades the subepithelial connective tissue), stage T2 (tumor invades the muscularis propria bladder wall), stage T3 (tumor invades the perivesical tissue), and stage T4 (tumor invades any of the following: prostate, uterus, vagina, pelvic wall, or abdominal wall) cancerous tissues, were measured by immunohistochemical analysis in clinical samples obtained from a total of 62 patients (49 men and 13 women) with UBC. Fig. 1 shows representative immunostaining of CCR7 protein, which was positively stained only in the cytoplasm and cell membranes of UBC cells. The majority of cases showed a heterogeneous staining pattern that was characterized by variable staining intensity within the same section or field (Fig. 1C). The average CCR7 staining

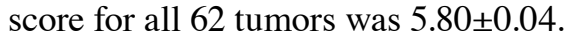

The clinicopathological data of all cases are summarized in Table I. The follow-up time was defined as the interval between surgery and death or between surgery and the last observation for surviving patients. The median (range) follow-up time after operation was 43.5 months (6-74 months). Thirty-nine patients were alive at the last follow-up examination; the others died of metastasis, local tumor invasion, severely compromised immunity and other causes. The median age of the study subjects at the time of treatment was 60.5 years (range, 34-77 years).

For statistical analyses, the mean CCR7 staining score was used as a cut-off to separate tissue sections with high CCR7 expression (final scores ranging from 6 to 12) from those with 

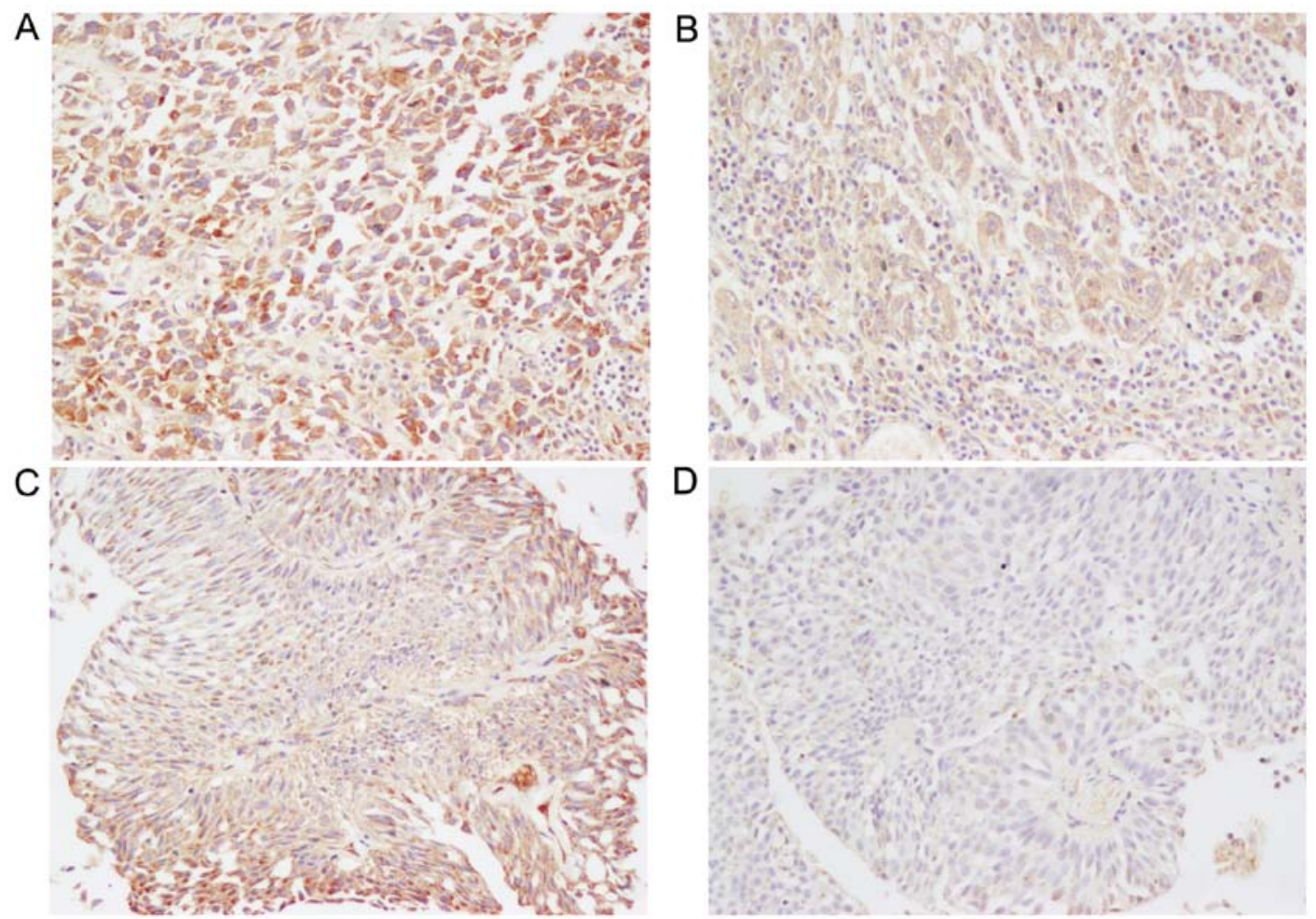

Figure 1. Immunohistochemical detection of CCR7 protein in patients with urinary bladder cancer. Intense, moderate and weak CCR7 expression in urinary bladder cancer patients is shown in panels (A, B and D), respectively. (C) The urinary bladder cancer case that showed a heterogeneous staining pattern was characterized by intense staining within the tumor periphery and moderate staining within the tumor center in the same field. Original magnification, $\mathrm{x} 200$.

Table I. Correlations between clinicopathological characteristics and CCR7, MLVD and MVD in 62 urinary bladder cancer patients.

\begin{tabular}{|c|c|c|c|c|c|c|c|c|}
\hline \multirow[b]{2}{*}{ Characteristics } & \multirow[b]{2}{*}{$\begin{array}{l}\text { No. of } \\
\text { cases }\end{array}$} & \multicolumn{3}{|c|}{ CCR7 expression } & \multicolumn{2}{|c|}{ MLVD } & \multicolumn{2}{|c|}{ MVD } \\
\hline & & $\begin{array}{l}\text { High } \\
(\mathrm{n}=40)\end{array}$ & $\begin{array}{l}\text { Low } \\
(n=22)\end{array}$ & P-value & $\begin{array}{l}\text { MLVD/HPF } \\
(\text { mean } \pm \text { SD) }\end{array}$ & P-value & $\begin{array}{l}\mathrm{MVD} / \mathrm{HPF} \\
(\text { mean } \pm \mathrm{SD})\end{array}$ & P-value \\
\hline Age (years) & & & & $0.618^{\mathrm{a}}$ & & $0.872^{\mathrm{c}}$ & & $0.632^{\mathrm{c}}$ \\
\hline$<60$ & 28 & 19 & 9 & & $6.40 \pm 2.06$ & & $34.52 \pm 6.33$ & \\
\hline$\geq 60$ & 34 & 21 & 13 & & $6.59 \pm 2.43$ & & $33.74 \pm 7.26$ & \\
\hline Sex & & & & $0.756^{\mathrm{b}}$ & & $0.463^{\mathrm{c}}$ & & $0.164^{\mathrm{c}}$ \\
\hline Male & 49 & 31 & 18 & & $6.37 \pm 2.53$ & & $34.83 \pm 6.27$ & \\
\hline Female & 13 & 9 & 4 & & $7.02 \pm 2.09$ & & $31.32 \pm 7.56$ & \\
\hline Primary tumor $(\mathrm{pT})^{\mathrm{e}}$ & & & & $0.015^{\mathrm{a}}$ & & $0.027^{\mathrm{c}}$ & & $0.016^{\mathrm{c}}$ \\
\hline pT1-T2 & 24 & 11 & 13 & & $3.87 \pm 2.37$ & & $30.81 \pm 8.36$ & \\
\hline pT3-T4 & 38 & 29 & 9 & & $8.17 \pm 3.16$ & & $36.17 \pm 7.24$ & \\
\hline Regional lymph nodes $(\mathrm{pN})^{\mathrm{e}}$ & & & & $0.008^{\mathrm{a}}$ & & $0.006^{c}$ & & $0.385^{\mathrm{c}}$ \\
\hline pNO & 40 & 21 & 19 & & $4.03 \pm 2.03$ & & $33.43 \pm 7.82$ & \\
\hline $\mathrm{pN} 1-\mathrm{N} 3$ & 22 & 19 & 3 & & $11.00 \pm 2.64$ & & $35.30 \pm 6.59$ & \\
\hline $\begin{array}{l}\text { Classification of } 2004 \\
\text { WHO grading system }\end{array}$ & & & & $0.010^{\mathrm{a}}$ & & $0.246^{\mathrm{d}}$ & & $0.447^{\mathrm{d}}$ \\
\hline PUNLMP & 5 & 2 & 3 & & $5.23 \pm 2.28$ & & $34.16 \pm 8.93$ & \\
\hline LGPUC & 24 & 11 & 13 & & $5.45 \pm 2.74$ & & $33.78 \pm 7.02$ & \\
\hline HGPUC & 33 & 27 & 6 & & $7.46 \pm 2.93$ & & $34.31 \pm 7.40$ & \\
\hline
\end{tabular}

PUNLMP, papillary urothelial neoplasm of low malignant potential; LGPUC, low grade urothelial carcinoma; HGPUC, high grade urothelial carcinoma; MLVD, microlymphatic vessel density; MVD, microvessel density; HPF, high power fields. ${ }^{\mathrm{a} C h i}$-square tests; ${ }^{\mathrm{b}} \mathrm{Fisher}$ 's exact test; cindependent samples t-test; ${ }^{\mathrm{d}}$ one-way analysis of variance. ${ }^{\mathrm{e}}$ Staging was confirmed based on the 2009 UICC-TNM staging system. 

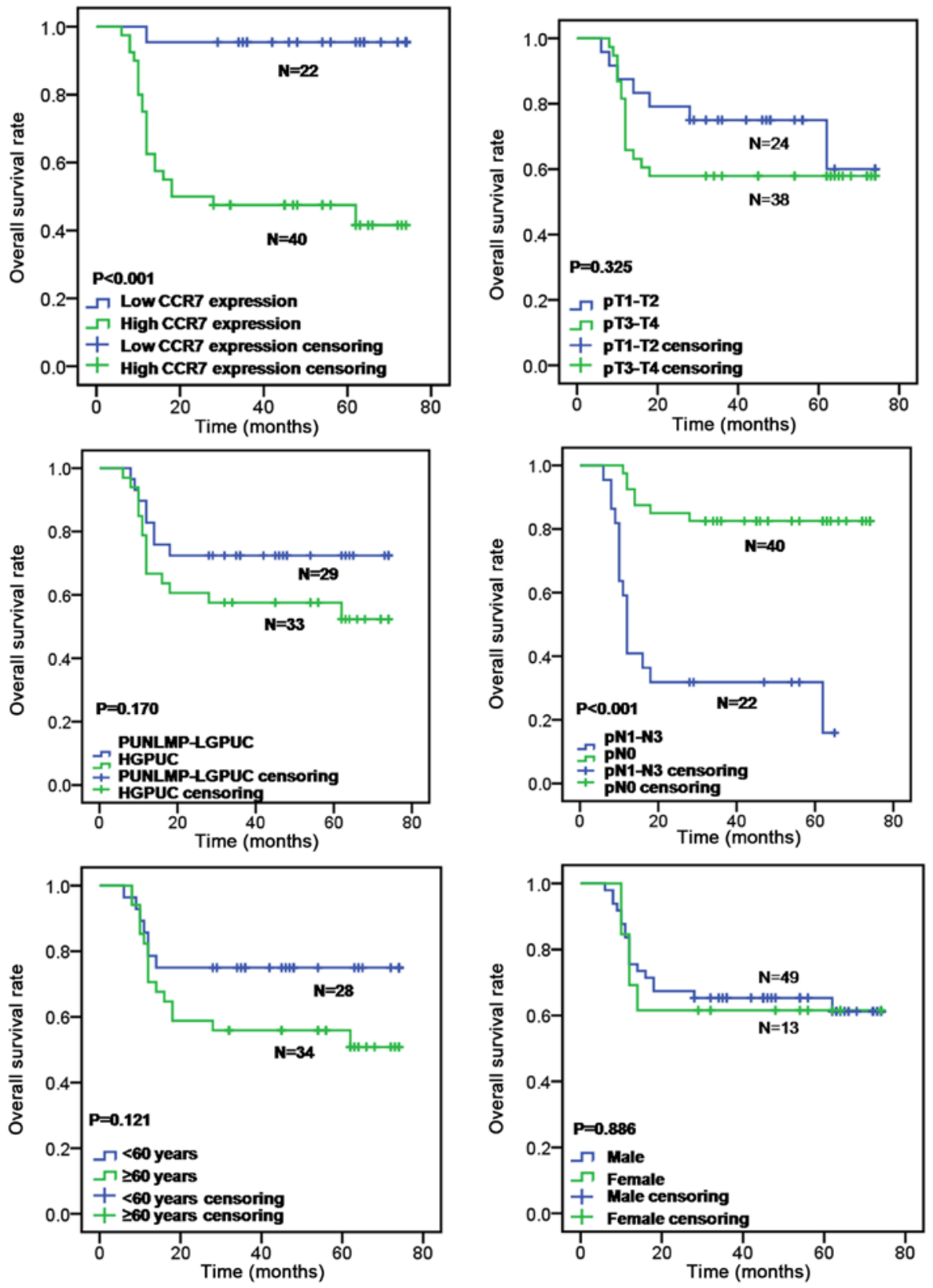

Figure 2. Kaplan-Meier curves for overall survival in 62 patients with urinary bladder cancer. The patients with high CCR7 expression and positive lymph node metastasis showed a significantly worse long-term overall survival rate than those with low CCR7 expression and negative lymph node metastasis by the log-rank test $(\mathrm{P}<0.001)$, whereas age $(\mathrm{P}=0.121)$, sex $(\mathrm{P}=0.886)$, primary tumor stage $(\mathrm{P}=0.325)$ and tumor grade $(\mathrm{P}=0.170)$ had no prognostic significance for overall survival.

Table II. Prognostic factors of urinary bladder cancer and their variable categorization.

\begin{tabular}{lcc}
\hline Prognostic factors & Variable names & Variable values \\
\hline Age & $\mathrm{X}_{1}$ & $0=<60$ years, $1=\geq 60$ years \\
Sex & $\mathrm{X}_{2}$ & $0=$ male, $1=$ female \\
pT & $\mathrm{X}_{3}$ & $0=\mathrm{pT} 1-\mathrm{T} 2,1=\mathrm{pT} 3-\mathrm{T} 4$ \\
pN & $\mathrm{X}_{4}$ & $0=\mathrm{pN} 1-\mathrm{N} 3,1=\mathrm{pN} 0$ \\
Pathological grade & $\mathrm{X}_{5}$ & $0=\mathrm{PUNLMP}-\mathrm{LGPUC}, 1=\mathrm{HGPUC}$ \\
CCR7 expression & $\mathrm{X}_{6}$ & $0=$ low, $1=$ high \\
Survival time & $\mathrm{t}$ & (months) \\
Survival status & $\mathrm{Y}$ & $0=$ censoring, $1=$ death
\end{tabular}

PUNLMP, papillary urothelial neoplasm of low malignant potential; LGPUC, low grade urothelial carcinoma; HGPUC, high grade urothelial carcinoma. 

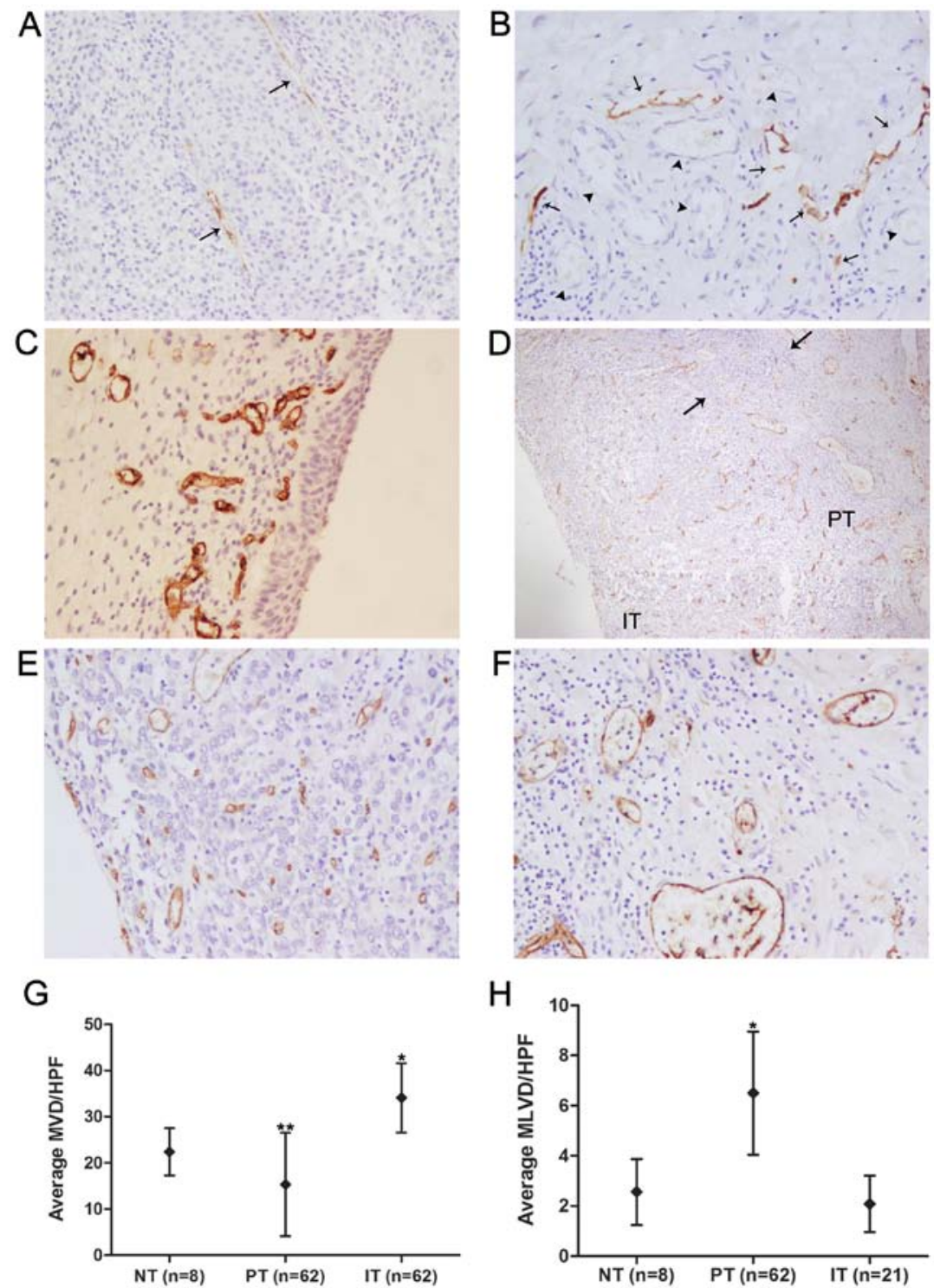

Figure 3. Immunohistochemical detection of D2-40 and CD34 proteins in patient with urinary bladder cancer. (A) Intratumoral lymphatic vessels (arrows) detected with D2-40 antibody in urinary bladder cancer samples presented collapsed and elongated size. (B) Peritumoral lymphatic vessels (arrows) detected with D2-40 antibody in urinary bladder cancer samples were found to be more dilated in the lumen, more numerous in vessel density and closer to anatomic locational correlation with blood vessels (arrowheads), which were identified by the characteristic of intraluminal erythrocytes compared with intratumoral lymphatics. (C) CD34-positive vessels representing blood vessels in normal control tissues were detected in the lamina propria and submucosa, while the epithelium expression was not found. (D) CD34-positive blood vessels were homogeneously present in the peritumoral (PT) and intratumoral areas (IT) of urinary bladder cancer cases, and inflammatory infiltration (the area between the two arrows) by lymphocytes was observed in the peritumoral area. Representative intratumoral and peritumoral blood vessels detected with CD34 antibody are shown, respectively (E and F). (G) Intratumoral MVD (n=62) was the highest, followed by the MVD of normal bladder tissues (NT, $n=8)$ and peritumoral MVD $(n=62)$. ${ }^{*} \mathrm{P}<0.05$ compared to the PT group and the NT group, ${ }^{* *} \mathrm{P}<0.05$ compared to the IT group and the NT group (one-way ANOVA followed by the SNK q-test). (H) Peritumoral MLVD (n=62) was the highest, followed by the MLVD of normal bladder tissues $(n=8)$ and intratumoral MLVD $(n=21)$. " $\mathrm{P}<0.001$ compared to the IT group and the NT group (one-way ANOVA followed by the SNK q-test). Original magnification, $\mathrm{x} 200$ in $\mathrm{A}, \mathrm{B}, \mathrm{C}, \mathrm{E}$ and F; $\mathrm{x} 40$ in D.

low CCR7 expression (final scores ranging from 0 to 4). The correlations between CCR7 immunoreactivity and the clinicopathological characteristics of the subjects are summarized in Table I. High expression of CCR7 protein was identified in $64.52 \%(40 / 62)$ of the tumors, and low expression was identified in $35.48 \%$ (22/62) of the tumors. CCR7 expression was significantly higher in patients with lymph node status of pN1-N3 than in patients with lymph node status of $\mathrm{pN} 0(\mathrm{P}=0.008$, Chi-square test) and was significantly associated with primary tumor stage $(\mathrm{P}=0.015$; Chi-square test $)$ and tumor grade $(\mathrm{P}=0.010$; Chi-square test $)$, whereas there was no significant correlation between CCR7 expression and patient age $(\mathrm{P}>0.05$;
Chi-square test) or sex ( $\mathrm{P}>0.05$; Fisher's exact test). Patients with high CCR7 expression exhibited a significantly worse overall survival rate than those with low CCR7 expression by the log-rank test $(\mathrm{P}<0.001$; Fig. 2). Furthermore, lymph node metastasis was also correlated with overall survival rate (logrank test, $\mathrm{P}<0.001$; Fig. 2), whereas patient's age (log-rank test, $\mathrm{P}=0.121$; Fig. 2), sex (log-rank test, $\mathrm{P}=0.886$; Fig. 2), primary tumor stage (log-rank test, $\mathrm{P}=0.325$; Fig. 2) and tumor grade (log-rank test, $\mathrm{P}=0.170$; Fig. 2) had no prognostic significance for overall survival. Prognostic factors of UBC and their variable assignment as determined by the multivariate analysis are shown in Table II. By multivariate analysis based on the Cox's 
Table III. Cox multivariate analysis of the factors associated with overall survival.

\begin{tabular}{|c|c|c|c|}
\hline Variables & HR & $95 \% \mathrm{CI}$ & P-value \\
\hline Age ( $<60$ vs. $\geq 60$ years $)$ & 0.854 & $0.264-2.761$ & 0.792 \\
\hline Sex (male vs. female) & 1.706 & $0.598-4.869$ & 0.318 \\
\hline pT (pT1-T2 vs. pT3-T4) & 1.583 & $0.603-4.157$ & 0.351 \\
\hline pN (pN1-N3 vs. pN0) & 0.211 & $0.083-0.534$ & 0.001 \\
\hline Pathological grade (PUNLMP-LGPUC vs. HGPUC) & 1.141 & $0.374-3.488$ & 0.816 \\
\hline CCR7 (low vs. high) & 10.413 & $1.242-87.313$ & 0.031 \\
\hline
\end{tabular}

PUNLMP, papillary urothelial neoplasm of low malignant potential; LGPUC, low grade urothelial carcinoma; HGPUC, high grade urothelial carcinoma. HR, hazard ratio; CI, confidence interval.

proportional hazard regression model, CCR7 protein expression level and $\mathrm{pN}$ were independent prognostic factors for overall survival in UBC patients (HR, 10.413, 95\% CI, 1.24287.313, $\mathrm{P}=0.031$ and HR, 0.211, 95\% CI, 0.083-0.534, $\mathrm{P}=0.001$, respectively), whereas, the patient's sex, age, tumor grade and primary tumor stage were not independent prognostic factors $(\mathrm{P}=0.318, \mathrm{P}=0.792, \mathrm{P}=0.816$ and $\mathrm{P}=0.351$, respectively $)$ (Table III). These results indicate that high levels of CCR7 expression may be associated with lymph node metastasis and poor overall survival in patients with UBC.

Identification of D2-40-positive lymphatic vessels and CD34positive blood vessels and measurement of MVD/MLVD. D2-40 positive staining was seen in thin-walled vessels devoid of erythrocytes, but no D2-40 staining was observed in tumor cells or blood vessels, indicating that D2-40 is specific for the lymphatic vasculature (Fig. 3A and B). D2-40-positive lymphatic vessels and CD34-positive blood vessels were detected in all tumor samples, and D2-40-positive lymphatic vessels were detected within peritumoral areas in $62(100 \%)$ cases and within intratumoral areas in $21(33.87 \%)$ cases. The morphological characteristics of D2-40-positive lymphatic vessels within intratumoral and peritumoral areas are shown in Fig. 3A and B. Peritumoral lymphatic vessels had more dilated lumina, were denser and more numerous, and showed a greater number of hotspots than intratumoral lymphatic vessels, which appeared collapsed and elongated. The anatomic locational correlation of peritumoral lymphatics with blood vessels was higher than that of intratumoral lymphatics (Fig. 3A and B). With regard to the eight normal bladder tissues obtained from obviously non-tumorous regions of bladder far from the tumor boundaries in patients who underwent radical cystectomy, both D2-40-positive lymphatic vessels and CD34-positive blood vessels were present in all normal control tissues, but were found only in the lamina propria and submucosa, and no epithelial expression was found (Fig. 3C). The average MLVD of normal bladder tissues was $(2.56 \pm 1.08) / \mathrm{HPF}$, which was significantly lower than the average peritumoral MLVD

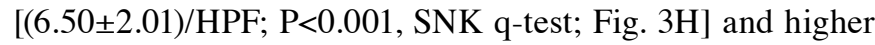
than the average intratumoral MLVD [(2.08 \pm 0.92$) / \mathrm{HPF}$; $\mathrm{P}>0.05$, SNK q-test; Fig. 3H], but the MLVD did not differ significantly between normal control tissues and intratumoral areas. Unlike the distribution of D2-40-positive vessels in serial tumor sections, CD34-positive blood vessels were homogeneously present in the peritumoral and intratumoral areas in the great majority of cases (Fig. 3D). The average MVDs of normal bladder tissues, peritumoral areas and intratumoral areas were $(22.40 \pm 4.59) / \mathrm{HPF},(15.33 \pm 10.23) / \mathrm{HPF}$ and $(34.09 \pm 7.26) / \mathrm{HPF}$, respectively, and the differences between any two groups were significant $(\mathrm{P}<0.05$, SNK q-test; Fig. $3 \mathrm{G})$. Inflammatory infiltration by lymphocytes was frequently observed in the peritumoral area (Fig. 3D).

Correlation of MVD/MLVD with clinicopathological parameters and CCR7 expression in 62 UBC patients. Microlymphatic vessel density per high-power field (MLVD/HPF) and microvessel density per high-power field (MVD/HPF) were assessed by immunohistochemical staining of 62 UBC tissues with antibodies against CD34 and D2-40. Due to the low detection rate and potentially non-functional characteristics of collapsed intratumoral lymphatic vessels, we only studied the relationship of peritumoral MLVD with clinical pathological parameters. As shown in Table I, a significantly higher MLVD/HPF was observed in patients with primary tumor stage of pT3-T4 $(\mathrm{P}=0.027)$ and lymph node status of $\mathrm{pN} 1-\mathrm{N} 3$ $(\mathrm{P}=0.006)$ than in patients with primary tumor stage of $\mathrm{pT} 1-\mathrm{T} 2$ and lymph node status of pN0. However, no obvious relationship was found between MLVD/HPF and patient age, sex or tumor grade (all $\mathrm{P}>0.05$ ). In addition, the data also showed that higher MVD/HPF was significantly related to a primary tumor stage of pT3-T4 $(\mathrm{P}=0.016)$ rather than pT1-T2. MVD/ HPF, however, was not significantly associated with patient age, sex, lymph node metastasis or tumor grade (all $\mathrm{P}>0.05$ ).

For further analysis of the possible correlation between CCR7 expression and MLVD/MVD, the 62 UBC patients were grouped into a low-CCR7-expression group and a high-CCR7expression group according to their CCR7 expression levels. Table IV shows that increased CCR7 expression was significantly correlated with higher MLVD/HPF $(\mathrm{P}=0.014)$ and higher MVD/HPF ( $\mathrm{P}=0.002)$. These results imply that CCR7 is a promoting factor that induces both lymphangiogenesis and angiogenesis but that it may be correlated with lymph node metastasis by virtue of its lymphangiogenic role rather than its angiogenic role.

Influence of the CCL21/CCR7 axis on the migration and invasion capacity of $U B C$ cells. Prior to the investigation of the effect of the CCL21/CCR7 axis on the migration and 
A
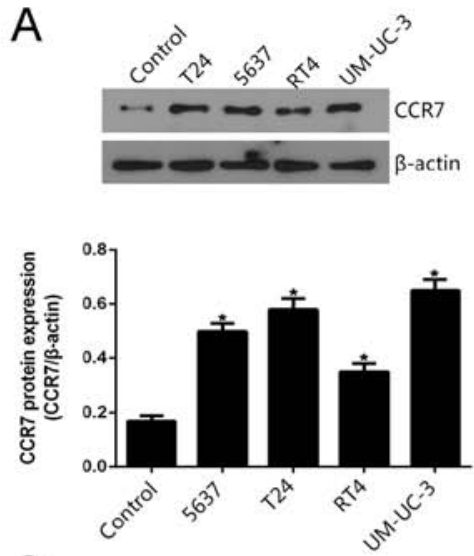

C
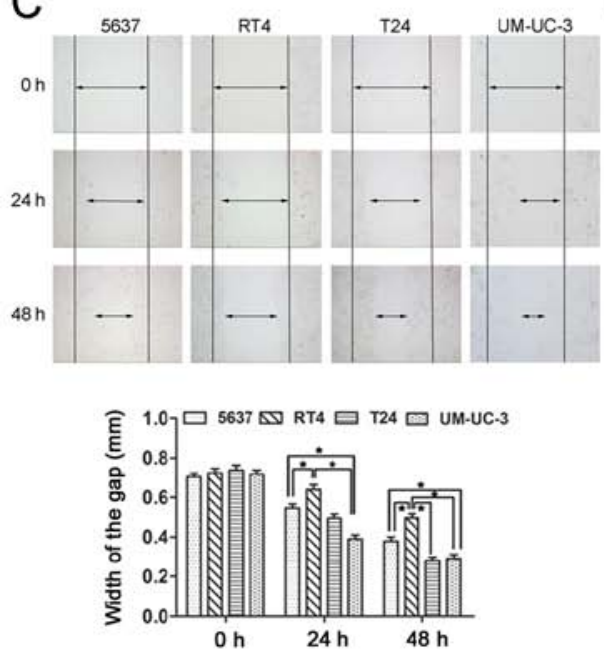

B

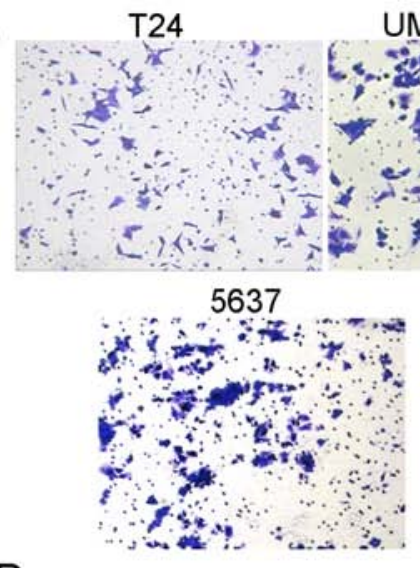

D

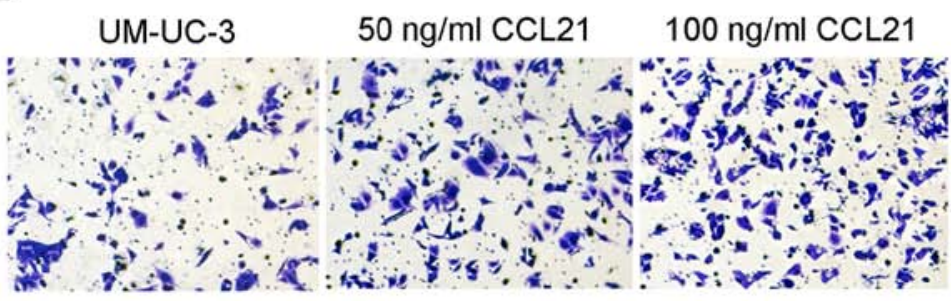

$200 \mathrm{ng} / \mathrm{ml} \mathrm{CCL} 21$

$300 \mathrm{ng} / \mathrm{ml} \mathrm{CCL21}$

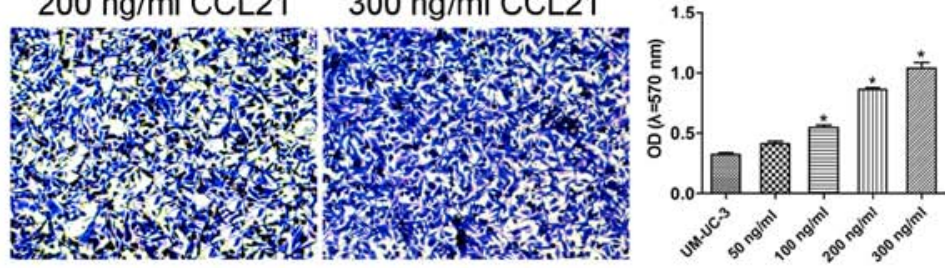

$\mathrm{E}$
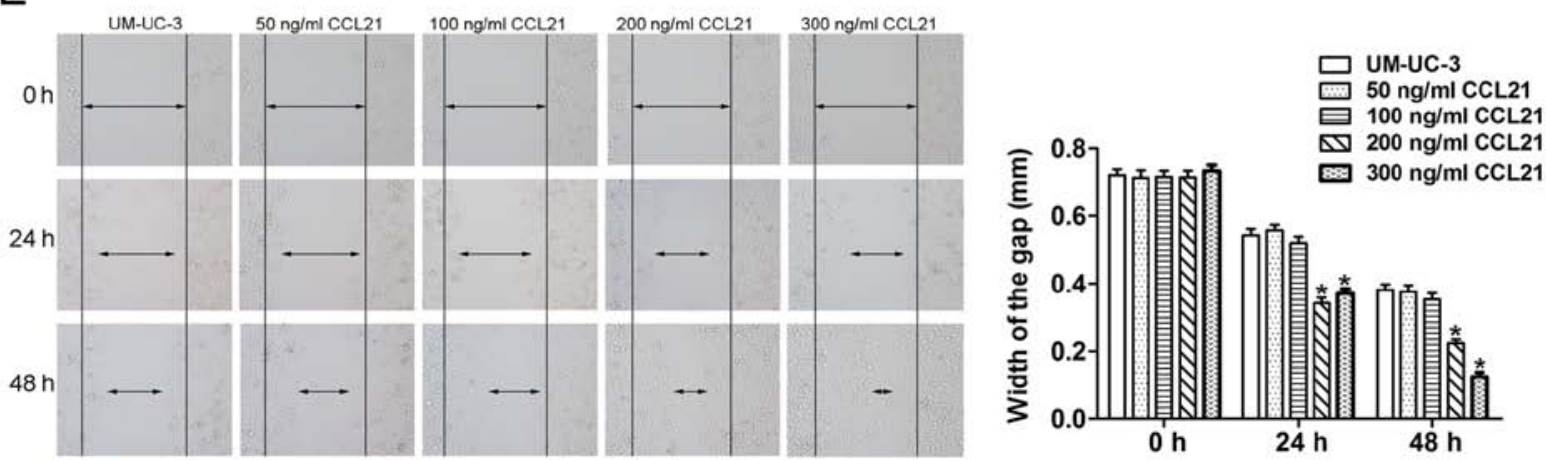

Figure 4. The CCL21/CCR7 axis modulates the invasion and migration by UM-UC-3 cells in a dose- and time-dependent manner. (A) Western blotting was used to detect the CCR7 expression in SV-HUC-1 control cells and T24, 5637, UM-UC-3 and RT4 urinary bladder cancer cells. "P<0.05 compared to the control group (one-way ANOVA followed by Dunnett's t-test). (B) Matrigel Transwell assay was used to determine the invasion ability of T24, 5637, UM-UC-3 and RT4 urinary bladder cancer cells. "P<0.05 compared to UM-UC-3 cells (one-way ANOVA followed by Dunnett's t-test). (C) The wound-healing assay was used to assess the migration ability of T24, 5637, UM-UC-3 and RT4 urinary bladder cancer cells. ${ }^{*} \mathrm{P}<0.05$ (one-way ANOVA followed by the SNK q-test). (D) Matrigel Transwell assay was used to determine the invasion ability of UM-UC-3 cells untreated or pretreated with $50100,200 \mathrm{and} 300 \mathrm{ng} / \mathrm{ml}$ CCL21 for $48 \mathrm{~h}$. "P<0.05 compared to untreated UM-UC-3 cells and to UM-UC-3 cells treated with $50 \mathrm{ng} / \mathrm{ml}$ CCL21 (one-way ANOVA followed by the LSD t-test). (E) The wound-healing assay was used to detect the migration ability of UM-UC-3 cells untreated or pretreated with 50, 100, $200 \mathrm{and} 300 \mathrm{ng} / \mathrm{ml} \mathrm{CCL21} \mathrm{for} 24$ and $48 \mathrm{~h} .{ }^{*} \mathrm{P}<0.05$ compared to UM-UC-3 group and to UM-UC-3 cells pretreated with 50 or $100 \mathrm{ng} / \mathrm{ml} \mathrm{CCL21}$ (one-way ANOVA followed by the LSD t-test). Each bar represents the mean \pm SD from three independent experiments.

invasion ability of UBC cells, we screened the constitutive expression of CCR7 in T24, 5637, UM-UC-3, RT4 UBC cells and SV-HUC-1 normal uroepithelial cells by western blot analysis. A significantly higher CCR7 expression level was observed in T24, 5637, UM-UC-3 and RT4 UBC cell lines than in SV-HUC-1 cell line which was used as the control cells (Fig. 4A). Furthermore, after treatment with $200 \mathrm{ng} / \mathrm{ml} \mathrm{CCL21,}$ the migration ability of the UM-UC-3 cells assessed by the mean of wound-healing assay was significantly enhanced at $24 \mathrm{~h}$ compared with other cells, and that of UM-UC-3 and T24 cells was significantly enhanced at $48 \mathrm{~h}$ compared with other cells (Fig. 4C). Similarly, the invasive ability of UM-UC-3 cells determined by the mean of Matrigel invasion assay using a polycarbonate membrane Transwell chamber was significantly 
Table IV. Correlations between CCR7 expression and MVD/MLVD in 62 urinary bladder cancer patients.

\begin{tabular}{lcccccr}
\hline & & \multicolumn{2}{c}{ MLVD } & & \multicolumn{2}{c}{ MVD } \\
\cline { 3 - 3 } CCR7 expression & No. of cases & MLVD/HPF (mean \pm SD) & P-value & & MVD/HPF (mean \pm SD) & P-value \\
\hline High & 40 & $8.11 \pm 2.39$ & $0.014^{\mathrm{a}}$ & & $37.03 \pm 8.03$ & $0.002^{\mathrm{a}}$ \\
Low & 22 & $3.57 \pm 1.84$ & & & $28.76 \pm 7.19$ & \\
\hline
\end{tabular}

MLVD, microlymphatic vessel density; MVD, microvessel density; HPF, high power fields. ${ }^{a}$ Independent samples t-test.
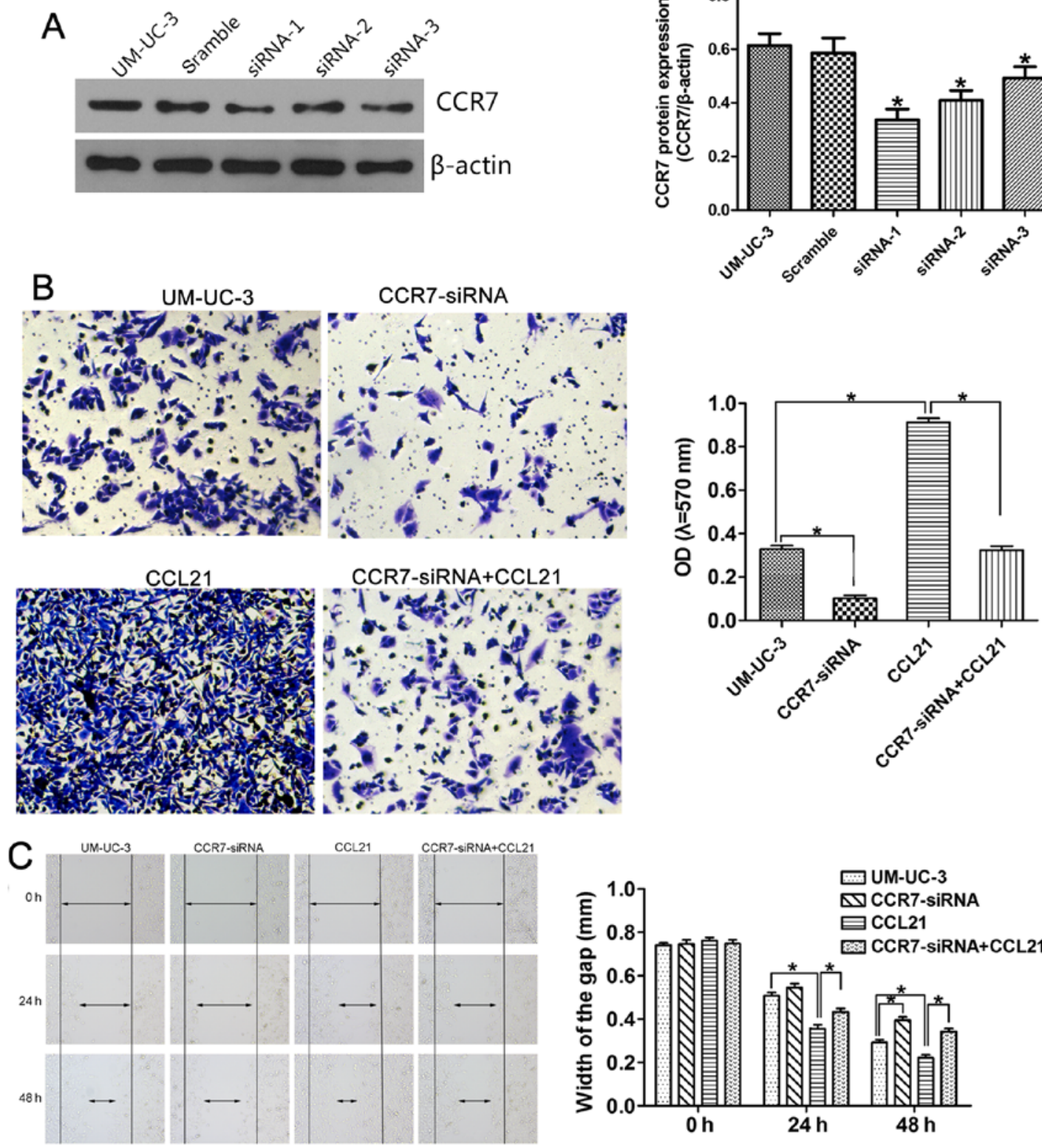

Figure 5. Gene silencing of CCR7 by siRNA inhibits migration and invasion by UM-UC-3 cells. UM-UC-3 cells were transfected with scrambled siRNA as a negative control or with CCR7 siRNA-1, siRNA-2 or siRNA-3. (A) CCR7 protein expression in transfected or non-transfected UM-UC-3 cells was evaluated using western blotting. "P<0.05 compared to non-transfected UM-UC-3 cells and to UM-UC-3 cells transfected with scrambled siRNA (one-way ANOVA followed by the LSD t-test). The invasion and migration capacities were measured using the Matrigel Transwell assay (B) and the wound-healing assay (C) in four independent groups consisting of a control group, a CCR7-siRNA group, a CCL21 group and a CCR7-siRNA+CCL21 group. "P<0.05 (one-way ANOVA followed by the LSD t-test). Each bar represents the mean \pm SD from three independent experiments.

higher than that of other UBC cells (Fig. 4B). Therefore, based on the results that the migration and invasion abilities of UM-UC-3 UBC cells were significantly higher than that of other UBC cells, the UM-UC-3 UBC cell line was selected 
A

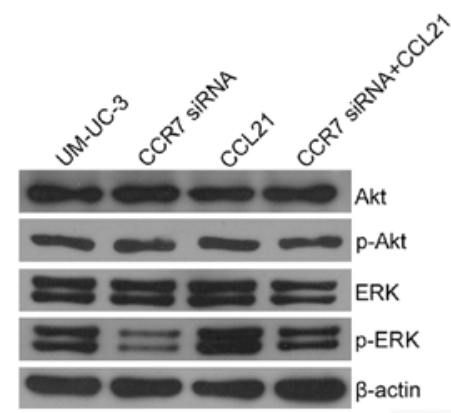

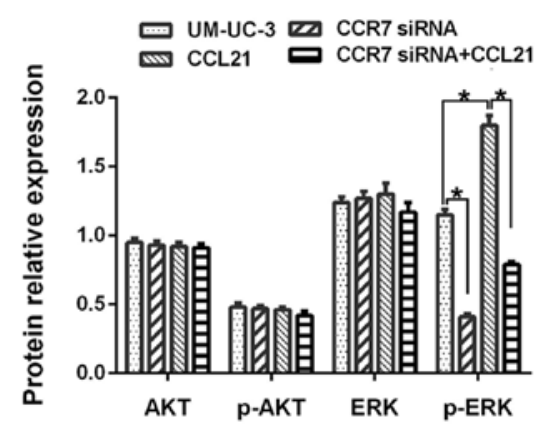

B
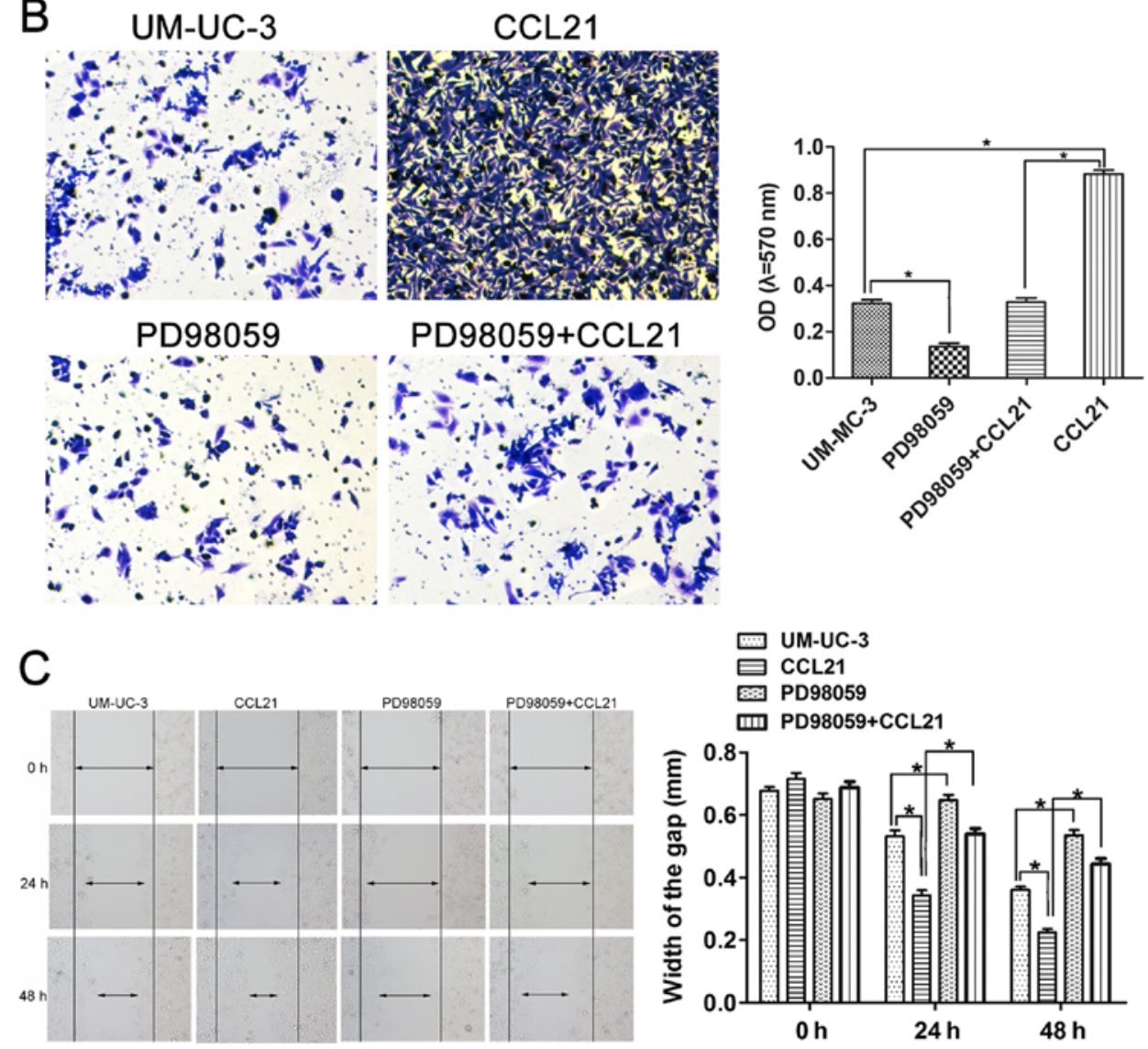

Figure 6. The ERK1/2 pathway is involved in CCL21/CCR7 axis-induced enhanced migration and invasion by UM-UC-3 cells. (A) Total-ERK1/2, phosphoERK1/2, total-AKT and phospho-AKT expression levels were detected by western blotting in the control group, the CCR7-siRNA group, the CCL21 group and the CCR7-siRNA+CCL21 group. "P<0.05 (one-way ANOVA followed by the LSD t-test). After sequential treatment with CCL21 and PD98059, UM-UC-3 cellular invasion and migration capacities were measured using Matrigel Transwell assays (B) and wound-healing assays (C). "P<0.05 (one-way ANOVA followed by the LSD t-test). Each bar represents the mean \pm SD from three independent experiments.

for the following in vitro study even though the T24, 5637 and UM-UC-3 cells show similar CCR7 protein expression level (Fig. 4A).

The effect of CCL21 at various concentrations on the invasion and migration capacity of UM-UC-3 cells is shown in Fig. 4D and E. To determine whether CCL21 was able to modulate invasion ability in UM-UC-3 cells, the Matrigel invasion assay was used to evaluate the cell's invasion ability. As presented in Fig. 4D, the OD of the cell suspensions of CCL21-treated cells increased gradually and significantly as the concentration of CCL21 was increased from 100 to $300 \mathrm{ng} / \mathrm{ml}$, indicating that CCL21 treatment significantly enhanced the invasion ability of UM-UC-3 cells in a dosedependent manner $(\mathrm{P}<0.05)$. When the UM-UC-3 cells were treated with CCL21 at 50 and $100 \mathrm{ng} / \mathrm{ml}$, the migration ability of the cells did not change significantly (Fig. 4E). However, as the treatment time increased and as the concentration of CCL21 protein was increased to $100 \mathrm{ng} / \mathrm{ml}$ and higher, an obvious effect of increased cell migration occurred. These results show that treatment of UM-UC-3 cells with CCL21 enhances their migration ability in a dose- and time-dependent manner.

To confirm the influence of the CCL21/CCR7 axis on the migration and invasion capacity of UM-UC-3 cells, small interfering RNAs (siRNAs) targeting the CCR7 gene were used for CCR7 knockdown, and exogenous CCL21 was used for CCR7 activation. Fig. 5A shows that all three CCR7 siRNA sequences (siRNA-1, siRNA-2 and siRNA-3) significantly depleted CCR7 expression in the UM-UC-3 cell line, as determined by western blotting, compared with cells transfected 
with negative control siRNA. UM-UC-3 cells transfected with CCR7 siRNA-1 were selected for use in the following in vitro study. The effects of CCR7 knockdown on the invasion behavior of the cells, as represented by the OD values, are shown in Fig. 5B. The OD values were $0.328 \pm 0.028$ in the control group, $0.102 \pm 0.024$ in UM-UC-3 cells transfected with CCR7 siRNA-1 (CCR7-siRNA group; $\mathrm{P}<0.05$ compared with the control group), $0.912 \pm 0.033$ in UM-UC-3 cells pretreated with $200 \mathrm{ng} / \mathrm{ml} \mathrm{CCL21} \mathrm{for} 48 \mathrm{~h}$ (CCL21 group; $\mathrm{P}<0.05$ compared with the control group), and $0.324 \pm 0.032$ in UM-UC-3 cells treated with $200 \mathrm{ng} / \mathrm{ml} \mathrm{CCL21} \mathrm{after} \mathrm{trans-}$ fection with CCR7 siRNA-1 (CCR7-siRNA+CCL21 group; $\mathrm{P}<0.05$ compared with the CCL21 group). These results indicate that CCR7 knockdown attenuates the enhancement by CCL21 of the invasive behavior of UM-UC-3 cells. CCL21 treatment significantly enhanced cell migration ability, and CCR7 knockdown by siRNA significantly abrogated the enhanced effect of CCL21 on the migration of UM-UC-3 cells (Fig. 5C). After transfection with CCR7 siRNA-1 for $24 \mathrm{~h}$, the difference in the migration ability of the CCR7-siRNA group and the control group was not statistically significant. However, when the UM-UC-3 cells were transfected for $48 \mathrm{~h}$, the difference was significant.

The ERK/AKT signaling pathway in the CCL21/CCR7 axis induces enhanced migration and invasion capacity of $U B C$ cells. To investigate whether CCL21/CCR7 interaction enhanced the invasion and migration ability of UM-UC-3 cells via the MEK/ERK1/2 pathway or the PI3K/AKT pathway, the expression levels of total-ERK1/2, phosphoERK1/2, total-AKT and phospho-AKT were first assessed using western blotting (Fig. 6A). The expression levels of total-ERK1/2, total-AKT and phospho-AKT in UM-UC-3 cells did not significantly change either after CCR7 gene knockdown or CCL21 treatment $(\mathrm{P}>0.05)$. However, the phospho-ERK1/2 protein level increased when the cells were treated with CCL21 and decreased when the CCR7 gene was silenced $(\mathrm{P}<0.05)$. These results indicate that CCL21/CCR7 interaction may modulate the action of the MEK/ERK signaling pathway but not that of the PI3K/AKT pathway in UM-UC-3 cells.

To determine how CCL21/CCR7 interaction promoted the invasion and migration functions of UM-UC-3 cells via the MEK/ERK1/2 pathway, PD98059 was used to inhibit the activation of MEK. PD98059 significantly suppressed the invasion ability of UM-UC-3 cells and abrogated the enhancement of the invasion ability of UM-UC-3 cells by CCL21/CCR7 $(\mathrm{P}<0.05$; Fig. 6B). Fig. 6C shows that inhibition of $\mathrm{MEK}$ (the upstream regulatory protein of ERK1/2) by PD98059 in UM-UC-3 cells led to significantly delayed wound healing at all times examined compared with the control group and significantly interfered with the rapid wound healing induced by CCL21 $(\mathrm{P}<0.05)$.

\section{Discussion}

The CC-chemokine receptor 7 (CCR7), which belongs to the Class A subfamily of $G$ protein-coupled receptors with seven transmembrane domains, is widely expressed in various types of immune cells including naive, regulatory and central memory $\mathrm{T}$ cells, naive $\mathrm{B}$ cells, double-negative and single-positive thymocytes, and (semi-) mature dendritic cells (DCs) and is functionally involved in the homing of various subpopulations of $\mathrm{T}$ cells and antigen-presenting DCs to the $\mathrm{T}$ cell areas of lymphoid tissues upon activation by the ligand of CCL21 $(23,24)$. Furthermore, aberrantly increased CCR7 expression has been reported in breast $(18,25)$, gastric $(22,26,27)$, colorectal (28-30), non-small cell lung $(31,32)$, cervical (33), SCC of the head and neck (34), prostate $(35,36)$, melanoma (37) and esophageal, oral and oropharyngeal SCC cancer (38-41) and is generally associated with lymph node metastasis and worse prognosis. In addition, a previous study conducted at our institution in which the CCR7 expression levels in 115 patients with UBC and 10 patients with benign prostatic hyperplasia (BPH) were compared found a significantly higher frequency of detectable CCR7 expression in the UBC group than in the $\mathrm{BPH}$ group and the clinical feasibility of CCR7 expression level as an independent predictive biomarker in the diagnosis of lymph node metastasis (42). However, little is known about the association of CCR7 expression with survival, prognosis, demographic factors or other clinicopathological features of UBC, such as tumor TNM staging and tumor differentiation, and the underlying mechanisms through which CCR7 affects the lymphatic metastasis of tumor cells remain obscure.

Our finding that high CCR7 expression was significantly correlated with lymph node metastasis and poor survival is consistent with the results of almost all related previous studies $(22,27,30,33,39,40)$. However, whether the CCR7 expression level can be used as an independent predictive factor in tumor prognosis remained controversial. Ding et al (39) reported that the CCR7 expression level was not identified as an independent prognostic factor in esophageal SCC by multivariate analysis. In contrast, some investigators reported that CCR7 was an independent prognostic factor for overall survival in gastric cancer, colorectal carcinoma, and cervical cancer $(27,28,33)$. It is unclear why these studies resulted in two completely different conclusions, and no explanations for this contradictory phenomenon are evident. We hypothesize that discrepancies in the weight ratio of CCR7 to other prometastatic factors, including MMP-9, IL-8, VEGF and EGFR, within different tumor environments as well as heterogeneity in tumor type, study population and study method may partially account for the above phenomena. Our multivariate analysis showed that high CCR7 expression and lymph node metastasis were independent prognostic factors for overall survival in $\mathrm{UBC}$, consistent with the findings reported by Ma et al (27), Gunther et al (28) and Kodama et al (33). We suggest that UBC patients who have negative lymph node metastasis but detectable high CCR7 expression should still be closely monitored, even though emphasis has formerly been placed on patients with positive lymph node involvement.

MVD, as assessed by immunohistochemistry using antibodies against CD34, CD31 or factor VIII-related antigen markers to identify vasculature, has been widely used as a surrogate marker for angiogenesis, which is characterized by neovascularization and is required for tumors to grow beyond a certain size and to metastasize to new sites (43). Of all these specific endothelial markers used for quantitative angiogenic studies, CD34 is widely accepted as the optimal marker especially in the invasive tumors due to its robustness 
and ease of use $(44,45)$, and thus, the antibody against CD34 was selected in this study. It is known that MVD is associated with tumor progression and survival in UBC (46-49). In addition, several studies have reported that altered MVD is also associated with lymph node metastasis and decreased survival rate in UBC (50-52). In contrast to the extensive studies on tumor-induced angiogenesis, little is known about MLVD and tumor-induced lymphangiogenesis, which has been evaluated using similiar methods as for MVD except that the antibodies used were LYVE-1-, D2-40/podoplaninor VEGFR-3-specific. In our literature review, we found that the use of VEGFR-3 as a marker for lymphatic vessels is controversial. A considerable amount of evidence shows that VEGFR-3 expression in tumors was detectable in the endothelium of lymphatic vessels, and VEGFR-3-positive vessels were counted when measuring MLVD (53-55). Additionally, however, it was reported that VEGFR-3 lacks specificity for lymphatic vessels in human tumors; tumoral VEGFR-3 expression was also present in the endothelium of blood vessels, and VEGFR-3 stained vessels were therefore used for MVD determination (56-58). The high specificity and sensitivity of D2-40 as a lymphatic endothelial marker to quantitatively assess lymphangiogenesis were verified by means of the immunohistochemical single staining using a single antibody to D2-40 (59), the immunohistochemical double staining using antibodies to D2-40 and CD34 (60) and the ultrastructure study using electron microscopy (61). Therefore, the antibody against D2-40 was selected as the specific lymphatic marker in this study. MLVD has been widely used as a marker for lymphangiogenesis characterized by the de novo formation of lymphatic vessels. With regard to the clinical significance and prognostic value of MLVD, a considerable number of studies reported that increased MLVD was statistically significantly correlated with lymph node metastasis and survival in head and neck SCC (62-64), breast (65), gastric cancer (66), prostate adenocarcinoma (67), cutaneous malignant melanoma $(68,69)$ and $\operatorname{UBC}(53,70)$. There is compelling evidence that pro-angiogenic and prolymphangiogenic factors (such as agents in the vascular growth factor family) trigger angiogenesis and lymphangiogenesis, respectively, and are related to adverse tumor outcomes. However, the role of CCR7 as a pro-angiogenic or pro-lymphangiogenic factor was unclear. Based on the notably significant relationship of lymph node metastasis to MLVD/MVD and CCR7 expression in human cancers, as discussed above, we speculate that CCR7 may play a pivotal role in lymph node metastasis and poor prognosis of UBC by acting as a pro-angiogenic or pro-lymphangiogenic factor to induce angiogenesis or lymphangiogenesis.

Our finding that MLVD was significantly higher in peritumoral areas than in normal control tissue suggested that at least some of the peritumoral lymphatics were indeed derived from the newly formed lymphatic vessels by lymphangiogenesis rather than being pre-existing vessels. The lower MLVD in intratumoral areas compared with the normal and peritumoral compartments is consistent with observations reported in other studies (62,71-73), as are the collapsed and elongated morphological characteristics of intratumoral lymphatics. These observations suggest a possible mechanism for the formation of intratumoral lymphatics in which the early-stage rapidly growing tumor grows into pre-existing lymphatic vessels to form partitions that ultimately surround the whole lymphatic vessel; the increased intratumoral pressure resulting from the tumor merisis then further compresses the separated lymphatics into a collapsed and elongated shape. Although this hypothetical non-lymphangiogenic pattern for the formation of intratumoral lymphatics requires further functional studies in vitro and in vivo to verify its validity, we speculate that intratumoral non-lymphangiogenic lymphatic vessels are probably non-functional for tumor progression. Reports by others (74-76) that no lymphatic vessels were detected within the intratumoral areas of malignant tumors of the female genital system further support our hypothesis. In view of the poor function of intratumoral lymphatics in tumor metastasis, the clinical significance of peritumoral lymphangiogenesis and peritumoral MLVD was analyzed. Our results showed that regional lymph node invasion was significantly associated with increased levels of peritumoral MLVD rather than MVD, consistent with the findings of other studies $(53,62,65-69)$ and suggesting that peritumoral lymphangiogenesis rather than angiogenesis is involved in the process of regional lymph node metastasis. On the other hand, in view of the significant correlation between MVD and tumor stage that was observed in this study (Table I), we presumed that tumor-associated angiogenesis is mainly involved in tumor growth and progression by acting as a pipeline for the transpor nutrients required for tumor cell growth. This presumption is consistent with our finding that MVD was highest within the intratumoral areas, followed by normal controls and peritumoral areas (Fig. 3G), indicating a greater demand for blood supply and nutrients within the tumor. Further analysis of correlations between CCR7 and MVD/MLVD revealed that high CCR7 expression level was associated with both increased MVD and MLVD, suggesting a promoting role of CCR7 in angiogenesis and lymphangiogenesis. Based on these findings, we concluded that, as a pro-angiogenic and pro-lymphangiogenic factor, CCR7 expression correlates with lymph node metastasis due to its lymphangiogenic role rather than its angiogenic role. A recent study reported the interesting finding that the CCL21/CCR7 axis is indirectly involved in breast cancerinduced lymphangiogenesis through regulation of the expression of VEGF-C (77). Whether the CCL21/CCR7 axis induces tumor lymphangiogenesis through a direct role as a pro-lymphangiogenic factor like the VEGF/VEGFR family or through indirect regulation of VEGF-C or VEGF-D remains an interesting question for future scientific research.

Several studies have shown that CCR7 activity is associated with migration and invasion by certain cancer cell lines (22,27,78-81). However, whether the upregulation and downregulation of CCR7 expression modulates the biological behavior of UBC cell lines in vitro is poorly defined, despite the fact that a higher CCR7 level was observed in UBC tissues than in normal controls (42). Our results demonstrate that CCL21/CCR7 interaction significantly enhances the migration and invasion capacity of human UM-UC-3 cells in a dose- and time-dependent manner. Moreover, knock down of the CCR7 gene by small interfering RNAs targeting CCR7 sequences was shown in the present study to significantly suppress the enhancement of migration and invasion by human UM-UC-3 cells that was induced by treatment of the cells with CCL21. 
These results further confirmed that the activation of CCR7 is responsible for the increased migration and invasion abilities of human UBC cells. Some previous studies reported that the CCL21/CCR7 axis enhances the migration and invasion of cancer cells via the ERK1/2 pathway (78), whereas others found that the CCL21/CCR7-induced enhanced behavior of cancer cells were mediated by the PI3K/AKT pathway (81). The present study shows that CCR7 activation by CCL21 treatment result in a significant increase in ERK1/2 phosphorylation but not AKT phosphorylation in UBC cells, and CCR7 knockdown by efficacious siRNA transfection significantly decreases ERK1/2 phosphorylation only. Furthermore, PD98059, a specific inhibitor of MEK, the upstream activator protein of ERK1/2, remarkably suppressed the enhanced invasion and migration abilities of UBC cells induced by CCL21. Based on these results, we came to a conclusion that the PI3K/ AKT and ERK pathways play a critical role in the carcinogenesis and progression of UBC $(78,81-83)$, but the ERK pathway may play a more important role in the CCL21/CCR7-induced progression of UBC than the AKT pathway.

This study is limited by its retrospective design and by the semi-quantitative immunohistochemical methodology used in the analysis of clinical tumor samples. Although immunohistochemistry has been widely used in the study of protein expression, it has inherent defects, including high variability in technical procedures and staining scoring standards in different studies. Another limitation of the present study is the isolation of the tumor cells from their microenvironment in our in vitro experiments. Animal models, especially the orthotopic xenograft model, which most closely mimics human primary tumor carcinogenesis, remain a crucial connection between cell-based experiments and the translation of novel agents into cancer therapeutics, and our results lack testing with in vivo experiments or appropriate animal models that provide a realistic microenvironment for tumor survival. A statistical methological defect of our research is the small sample size of 62 subjects that may result in the reduced test power $(1-\beta)$ and the increased type II error $(\beta)$.

In conclusion, this study provides novel insights into the multifaceted role played by the CCL21/CCR7 chemoaxis in the complex mechanics of lymph node metastasis in patients with UBC. On the one hand, CCR7 is a promoting factor that induces both lymphangiogenesis and angiogenesis; however, it may correlate with lymph node metastasis due to its lymphangiogenic role rather than due to its angiogenic role. On the other hand, the CCL21/CCR7 chemoaxis promotes the migration and invasion by UBC cells via the MEK/ERK1/2 signaling pathway rather than the PI3K/AKT pathway. These insights into the mechanisms of CCL21/CCR7-mediated migration, invasion and lymph node metastasis in UBC enable us to inhibit the molecular processes involved in these events and thereby deliver therapeutic benefit to patients with advanced disease.

\section{References}

1. Ploeg M, Aben KK and Kiemeney LA: The present and future burden of urinary bladder cancer in the world. World J Urol 27: 289-293, 2009

2. Johansson SL and Cohen SM: Epidemiology and etiology of bladder cancer. Semin Surg Oncol 13: 291-298, 1997.
3. Siegel RL, Miller KD and Jemal A: Cancer statistics, 2016. CA Cancer J Clin 66: 7-30, 2016.

4. Metts MC, Metts JC, Milito SJ and Thomas CR Jr: Bladder cancer: A review of diagnosis and management. J Natl Med Assoc 92: 285-294, 2000.

5. Xu X, Chen H, Lin Y, Hu Z, Mao Y, Wu J, Xu X, Zhu Y, Li S, Zheng X, et al: MicroRNA-409-3p inhibits migration and invasion of bladder cancer cells via targeting c-Met. Mol Cells 36: 62-68, 2013.

6. Babjuk M, Burger M, Zigeuner R, Shariat SF, van Rhijn BW, Compérat E, Sylvester RJ, Kaasinen E, Böhle A, Palou Redorta J, et al; European Association of Urology: EAU guidelines on non-muscle-invasive urothelial carcinoma of the bladder: Update 2013. Eur Urol 64: 639-653, 2013.

7. Luke C, Tracey E, Stapleton A and Roder D: Exploring contrary trends in bladder cancer incidence, mortality and survival: Implications for research and cancer control. Intern Med J 40: 357-362, 2010.

8. Zuiverloon TC, Nieuweboer AJ, Vékony H, Kirkels WJ, Bangma $\mathrm{CH}$ and Zwarthoff EC: Markers predicting response to bacillus Calmette-Guérin immunotherapy in high-risk bladder cancer patients: A systematic review. Eur Urol 61: 128-145, 2012.

9. Abdollah F, Gandaglia G, Thuret R, Schmitges J, Tian Z, Jeldres C, Passoni NM, Briganti A, Shariat SF, Perrotte P, et al: Incidence, survival and mortality rates of stage-specific bladder cancer in United States: A trend analysis. Cancer Epidemiol 37: 219-225, 2013.

10. Meeks JJ, Bellmunt J, Bochner BH, Clarke NW, Daneshmand S, Galsky MD, Hahn NM, Lerner SP, Mason M, Powles T, et al: A systematic review of neoadjuvant and adjuvant chemotherapy for muscle-invasive bladder cancer. Eur Urol 62: 523-533, 2012.

11. Itesako T, Seki N, Yoshino $\mathrm{H}$, Chiyomaru T, Yamasaki $\mathrm{T}$, Hidaka H, Yonezawa T, Nohata N, Kinoshita T, Nakagawa M, et al: The microRNA expression signature of bladder cancer by deep sequencing: The functional significance of the miR-195/497 cluster. PLoS One 9: e84311, 2014.

12. Gupta GP and Massagué J: Cancer metastasis: Building a framework. Cell 127: 679-695, 2006.

13. Siegel R, Ma J, Zou Z and Jemal A: Cancer statistics, 2014. CA Cancer J Clin 64: 9-29, 2014.

14. Shariat SF, Karakiewicz PI, Palapattu GS, Amiel GE, Lotan Y, Rogers CG, Vazina A, Bastian PJ, Gupta A, Sagalowsky A, et al: Nomograms provide improved accuracy for predicting survival after radical cystectomy. Clin Cancer Res 12: 6663-6676, 2006.

15. Habuchi T, Marberger M, Droller MJ, Hemstreet GP III, Grossman HB, Schalken JA, Schmitz-Dräger BJ, Murphy WM, Bono AV, Goebell P, et al: Prognostic markers for bladder cancer: International Consensus Panel on bladder tumor markers. Urology 66 (Suppl 1): 64-74, 2005.

16. Bol MG, Baak JP, Buhr-Wildhagen S, Kruse AJ, Kjellevold KH, Janssen EA, Mestad O and Øgreid P: Reproducibility and prognostic variability of grade and lamina propria invasion in stages Ta, T1 urothelial carcinoma of the bladder. J Urol 169: 1291-1294, 2003.

17. Guo JC, Li J, Zhou L, Yang JY, Zhang ZG, Liang ZY, Zhou WX, You L, Zhang TP and Zhao YP: CXCL12-CXCR7 axis contributes to the invasive phenotype of pancreatic cancer. Oncotarget 7: 62006-62018, 2016.

18. Müller A, Homey B, Soto H, Ge N, Catron D, Buchanan ME, McClanahan T, Murphy E, Yuan W, Wagner SN, et al: Involvement of chemokine receptors in breast cancer metastasis. Nature 410: 50-56, 2001.

19. Yasuoka H, Tsujimoto M, Yoshidome K, Nakahara M, Kodama R, Sanke T and Nakamura Y: Cytoplasmic CXCR4 expression in breast cancer: Induction by nitric oxide and correlation with lymph node metastasis and poor prognosis. BMC Cancer 8: 340, 2008.

20. Yu T, Wu Y, Helman JI, Wen Y, Wang C and Li L: CXCR4 promotes oral squamous cell carcinoma migration and invasion through inducing expression of MMP-9 and MMP-13 via the ERK signaling pathway. Mol Cancer Res 9: 161-172, 2011.

21. Kato T, Fujita Y, Nakane K, Mizutani K, Terazawa R, Ehara H, Kanimoto Y, Kojima T, Nozawa Y, Deguchi T, et al: CCR1/ CCL5 interaction promotes invasion of taxane-resistant PC3 prostate cancer cells by increasing secretion of MMPs $2 / 9$ and by activating ERK and Rac signaling. Cytokine 64: 251-257, 2013. 
22. Mashino K, Sadanaga N, Yamaguchi H, Tanaka F, Ohta M, Shibuta K, Inoue $\mathrm{H}$ and Mori M: Expression of chemokine receptor CCR7 is associated with lymph node metastasis of gastric carcinoma. Cancer Res 62: 2937-2941, 2002.

23. Comerford I, Harata-Lee Y, Bunting MD, Gregor C, Kara EE and McColl SR: A myriad of functions and complex regulation of the CCR7/CCL19/CCL21 chemokine axis in the adaptive immune system. Cytokine Growth Factor Rev 24: 269-283, 2013.

24. Förster R, Davalos-Misslitz AC and Rot A: CCR7 and its ligands: Balancing immunity and tolerance. Nat Rev Immunol 8: 362-371, 2008.

25. Cabioglu N, Yazici MS, Arun B, Broglio KR, Hortobagyi GN, Price JE and Sahin A: CCR7 and CXCR4 as novel biomarkers predicting axillary lymph node metastasis in T1 breast cancer. Clin Cancer Res 11: 5686-5693, 2005.

26. Ishigami S, Natsugoe S, Nakajo A, Tokuda K, Uenosono $Y$, Arigami T, Matsumoto M, Okumura $\mathrm{H}$, Hokita $\mathrm{S}$ and Aikou T: Prognostic value of CCR7 expression in gastric cancer. Hepatogastroenterology 54: 1025-1028, 2007.

27. Ma H, Gao L, Li S, Qin J, Chen L, Liu X, Xu P, Wang F, Xiao H, Zhou S, et al: CCR7 enhances TGF- $\beta 1$-induced epithelialmesenchymal transition and is associated with lymph node metastasis and poor overall survival in gastric cancer. Oncotarget 6: 24348-24360, 2015 .

28. Günther K, Leier J, Henning G, Dimmler A, Weissbach R, Hohenberger W and Förster R: Prediction of lymph node metastasis in colorectal carcinoma by expressionof chemokine receptor CCR7. Int J Cancer 116: 726-733, 2005.

29. Yu S, Duan J, Zhou Z, Pang Q, Wuyang J, Liu T, He X, Xinfa L and Chen Y: A critical role of CCR7 in invasiveness and metastasis of SW620 colon cancer cell in vitro and in vivo. Cancer Biol Ther 7: 1037-1043, 2008.

30. Malietzis G, Lee GH, Bernardo D, Blakemore AI, Knight SC, Moorghen M, Al-Hassi HO and Jenkins JT: The prognostic significance and relationship with body composition of CCR7positive cells in colorectal cancer. J Surg Oncol 112: 86-92, 2015.

31. Koizumi K, Kozawa Y, Ohashi Y, Nakamura ES, Aozuka Y, Sakurai H, Ichiki K, Doki Y, Misaki T and Saiki I: CCL21 promotes the migration and adhesion of highly lymph node metastatic human non-small cell lung cancer Lu-99 in vitro. Oncol Rep 17: 1511-1516, 2007.

32. Takanami I: Overexpression of CCR7 mRNA in nonsmall cell lung cancer: Correlation with lymph node metastasis. Int J Cancer 105: 186-189, 2003

33. Kodama J, Hasengaowa, Kusumoto T, Seki N, Matsuo T, Ojima Y, Nakamura K, Hongo A and Hiramatsu Y: Association of CXCR4 and CCR7 chemokine receptor expression and lymph node metastasis in human cervical cancer. Ann Oncol 18: 70-76, 2007.

34. Wang J, Xi L, Hunt JL, Gooding W, Whiteside TL, Chen Z, Godfrey TE and Ferris RL: Expression pattern of chemokine receptor 6 (CCR6) and CCR7 in squamous cell carcinoma of the head and neck identifies a novel metastatic phenotype. Cancer Res 64: 1861-1866, 2004

35. Yousefieh N, Hahto SM, Stephens AL and Ciavarra RP: Regulated expression of CCL21 in the prostate tumor microenvironment inhibits tumor growth and metastasis in an orthotopic model of prostate cancer. Cancer Microenviron 2: 59-67, 2009.

36. Heresi GA, Wang J, Taichman R, Chirinos JA, Regalado JJ, Lichtstein DM and Rosenblatt JD: Expression of the chemokine receptor CCR7 in prostate cancer presenting with generalized lymphadenopathy: Report of a case, review of the literature, and analysis of chemokine receptor expression. Urol Oncol 23: 261-267, 2005.

37. Mori T, Kim J, Yamano T, Takeuchi H, Huang S, Umetani N, Koyanagi K and Hoon DS: Epigenetic up-regulation of C-C chemokine receptor 7 and $\mathrm{C}-\mathrm{X}-\mathrm{C}$ chemokine receptor 4 expression in melanoma cells. Cancer Res 65: 1800-1807, 2005.

38. Ishida K, Iwahashi M, Nakamori M, Nakamura M, Yokoyama S, Iida T, Naka T, Nakamura Y and Yamaue H: High CCR7 mRNA expression of cancer cells is associated with lymph node involvement in patients with esophageal squamous cell carcinoma. Int J Oncol 34: 915-922, 2009.

39. Ding Y, Shimada Y, Maeda M, Kawabe A, Kaganoi J, Komoto I, Hashimoto Y, Miyake M, Hashida H and Imamura M: Association of $\mathrm{CC}$ chemokine receptor 7 with lymph node metastasis of esophageal squamous cell carcinoma. Clin Cancer Res 9: 34063412,2003
40. Shi M, Chen D, Yang D and Liu XY: CCL21-CCR7 promotes the lymph node metastasis of esophageal squamous cell carcinoma by up-regulating MUC1. J Exp Clin Cancer Res 34: 149, 2015.

41. Shang ZJ, Liu K and Shao Z: Expression of chemokine receptor CCR7 is associated with cervical lymph node metastasis of oral squamous cell carcinoma. Oral Oncol 45: 480-485, 2009.

42. Chen J, Cui YU, Liu L, Li C, Tang Y, Zhou XU, Qi L and Zu X: CCR7 as a predictive biomarker associated with computed tomography for the diagnosis of lymph node metastasis in bladder carcinoma. Oncol Lett 11: 735-740, 2016.

43. Elfiky AA and Rosenberg JE: Targeting angiogenesis in bladder cancer. Curr Oncol Rep 11: 244-249, 2009.

44. Vermeulen PB, Gasparini G, Fox SB, Toi M, Martin L, McCulloch P, Pezzella F, Viale G, Weidner N, Harris AL, et al: Quantification of angiogenesis in solid human tumours: An international consensus on the methodology and criteria of evaluation. Eur J Cancer 32A: 2474-2484, 1996.

45. Vermeulen PB, Gasparini G, Fox SB, Colpaert C, Marson LP Gion M, Beliën JA, de Waal RM, Van Marck E, Magnani E, et al: Second international consensus on the methodology and criteria of evaluation of angiogenesis quantification in solid human tumours. Eur J Cancer 38: 1564-1579, 2002.

46. Dickinson AJ, Fox SB, Persad RA, Hollyer J, Sibley GN and Harris AL: Quantification of angiogenesis as an independent predictor of prognosis in invasive bladder carcinomas. Br J Urol 74: 762-766, 1994

47. Bochner BH, Cote RJ, Weidner N, Groshen S, Chen SC, Skinner DG and Nichols PW: Angiogenesis in bladder cancer: Relationship between microvessel density and tumor prognosis. J Natl Cancer Inst 87: 1603-1612, 1995.

48. Goddard JC, Sutton CD, Furness PN, O'Byrne KJ and Kockelbergh RC: Microvessel density at presentation predicts subsequent muscle invasion in superficial bladder cancer. Clin Cancer Res 9: 2583-2586, 2003.

49. Canoğlu A, Göğüis C, Bedük Y, Orhan D, Tulunay O and Baltaci S: Microvessel density as a prognostic marker in bladder carcinoma: Correlation with tumor grade, stage and prognosis. Int Urol Nephrol 36: 401-405, 2004.

50. Chaudhary R, Bromley M, Clarke NW, Betts CD, Barnard RJ, Ryder WD and Kumar S: Prognostic relevance of micro-vessel density in cancer of the urinary bladder. Anticancer Res 19: 3479-3484, 1999.

51. Jaeger TM, Weidner N, Chew K, Moore DH, Kerschmann RL, Waldman FM and Carroll PR: Tumor angiogenesis correlates with lymph node metastases in invasive bladder cancer. J Urol 154: 69-71, 1995.

52. Shariat SF, Youssef RF, Gupta A, Chade DC, Karakiewicz PI, Isbarn H, Jeldres C, Sagalowsky AI, Ashfaq R and Lotan Y: Association of angiogenesis related markers with bladder cancer outcomes and other molecular markers. J Urol 183: 1744-1750, 2010.

53. Zhou M, He L, Zu X, Zhang H, Zeng H and Qi L: Lymphatic vessel density as a predictor of lymph node metastasis and its relationship with prognosis in urothelial carcinoma of the bladder. BJU Int 107: 1930-1935, 2011

54. Jacquemier J, Mathoulin-Portier MP, Valtola R, CharafeJauffret E, Geneix J, Houvenaeghel G, Puig B, Bardou VJ, Hassoun J, Viens P, et al: Prognosis of breast-carcinoma lymphagenesis evaluated by immunohistochemical investigation of vascular-endothelial-growth-factor receptor 3. Int J Cancer 89: 69-73, 2000.

55. Zeng Y, Opeskin K, Baldwin ME, Horvath LG, Achen MG, Stacker SA, Sutherland RL and Williams ED: Expression of vascular endothelial growth factor receptor-3 by lymphatic endothelial cells is associated with lymph node metastasis in prostate cancer. Clin Cancer Res 10: 5137-5144, 2004

56. Longatto Filho A, Martins A, Costa SM and Schmitt FC: VEGFR-3 expression in breast cancer tissue is not restricted to lymphatic vessels. Pathol Res Pract 201: 93-99, 2005.

57. Valtola R, Salven P, Heikkilä P, Taipale J, Joensuu H, Rehn M, Pihlajaniemi T, Weich H, deWaal R and Alitalo K: VEGFR-3 and its ligand VEGF-C are associated with angiogenesis in breast cancer. Am J Pathol 154: 1381-1390, 1999.

58. Partanen TA, Alitalo K and Miettinen M: Lack of lymphatic vascular specificity of vascular endothelial growth factor receptor 3 in 185 vascular tumors. Cancer 86: 2406-2412, 1999.

59. Kahn HJ, Bailey D and Marks A: Monoclonal antibody D2-40, a new marker of lymphatic endothelium, reacts with Kaposi's sarcoma and a subset of angiosarcomas. Mod Pathol 15: 434-440, 2002 . 
60. Afonso J, Santos LL, Amaro T, Lobo F and Longatto-Filho A The aggressiveness of urothelial carcinoma depends to a large extent on lymphovascular invasion - the prognostic contribution of related molecular markers. Histopathology 55: 514-524, 2009.

61. Braun M, Flucke U, Debald M, Walgenbach-Bruenagel G, Walgenbach KJ, Höller T, Pölcher M, Wolfgarten M, Sauerwald A, Keyver-Paik M, et al: Detection of lymphovascular invasion in early breast cancer by D2-40 (podoplanin): A clinically useful predictor for axillary lymph node metastases. Breast Cancer Res Treat 112: 503-511, 2008.

62. Franchi A, Gallo O, Massi D, Baroni G and Santucci M: Tumor lymphangiogenesis in head and neck squamous cell carcinoma: A morphometric study with clinical correlations. Cancer 101: 973-978, 2004.

63. Beasley NJ, Prevo R, Banerji S, Leek RD, Moore J, van Trappen P, Cox G, Harris AL and Jackson DG: Intratumoral lymphangiogenesis and lymph node metastasis in head and neck cancer. Cancer Res 62: 1315-1320, 2002.

64. Maula SM, Luukkaa M, Grénman R, Jackson D, Jalkanen S and Ristamäki R: Intratumoral lymphatics are essential for the metastatic spread and prognosis in squamous cell carcinomas of the head and neck region. Cancer Res 63: 1920-1926, 2003.

65. Nakamura Y, Yasuoka H, Tsujimoto M, Imabun S, Nakahara M, Nakao K, Nakamura M, Mori I and Kakudo K: Lymph vessel density correlates with nodal status, VEGF-C expression, and prognosis in breast cancer. Breast Cancer Res Treat 91: 125-132, 2005.

66. Wang XL, Fang JP, Tang RY and Chen XM: Different significance between intratumoral and peritumoral lymphatic vessel density in gastric cancer: A retrospective study of 123 cases. BMC Cancer 10: 299, 2010.

67. Roma AA, Magi-Galluzzi C, Kral MA, Jin TT, Klein EA and Zhou M: Peritumoral lymphatic invasion is associated with regional lymph node metastases in prostate adenocarcinoma. Mod Pathol 19: 392-398, 2006.

68. Dadras SS, Paul T, Bertoncini J, Brown LF, Muzikansky A, Jackson DG, Ellwanger U, Garbe C, Mihm MC and Detmar M: Tumor lymphangiogenesis: A novel prognostic indicator for cutaneous melanoma metastasis and survival. Am J Pathol 162: 1951-1960, 2003.

69. Dadras SS, Lange-Asschenfeldt B, Velasco P, Nguyen L, Vora A, Muzikansky A, Jahnke K, Hauschild A. Hirakawa S, Mihm MC, et al: Tumor lymphangiogenesis predicts melanoma metastasis to sentinel lymph nodes. Mod Pathol 18: 1232-1242, 2005.

70. Ma Y, Hou Y, Liu B, Li X, Yang S and Ma J: Intratumoral lymphatics and lymphatic vessel invasion detected by D2-40 are essential for lymph node metastasis in bladder transitional cell carcinoma. Anat Rec (Hoboken) 293: 1847-1854, 2010.

71. Fernández MI, Bolenz C, Trojan L, Steidler A, Weiss C, Alken P, Grobholz R and Michel MS: Prognostic implications of lymphangiogenesis in muscle-invasive transitional cell carcinoma of the bladder. Eur Urol 53: 571-578, 2008.
72. Miyata Y, Kanda S, Ohba K, Nomata K, Hayashida Y, Eguchi J, Hayashi T and Kanetake H: Lymphangiogenesis and angiogenesis in bladder cancer: prognostic implications and regulation by vascular endothelial growth factors-A, $-\mathrm{C}$, and -D. Clin Cancer Res 12: 800-806, 2006.

73. Liang P, Hong JW, Ubukata H, Liu HR, Watanabe Y, Katano M, Motohashi G, Kasuga T, Nakada I and Tabuchi T: Increased density and diameter of lymphatic microvessels correlate with lymph node metastasis in early stage invasive colorectal carcinoma. Virchows Arch 448: 570-575, 2006.

74. Williams CS, Leek RD, Robson AM, Banerji S, Prevo R, Harris AL and Jackson DG: Absence of lymphangiogenesis and intratumoural lymph vessels in human metastatic breast cancer. J Pathol 200: 195-206, 2003.

75. Birner P, Schindl M, Obermair A, Plank C, Breitenecker G, Kowalski $\mathrm{H}$ and Oberhuber G: Lymphatic microvessel density in epithelial ovarian cancer: Its impact on prognosis. Anticancer Res 20: 2981-2985, 2000.

76. Schoppmann SF, Birner P, Stöckl J, Kalt R, Ullrich R, Caucig C, Kriehuber E, Nagy K, Alitalo K and Kerjaschki D: Tumorassociated macrophages express lymphatic endothelial growth factors and are related to peritumoral lymphangiogenesis. Am J Pathol 161: 947-956, 2002.

77. Tutunea-Fatan E, Majumder M, Xin X and Lala PK: The role of CCL21/CCR7 chemokine axis in breast cancer-induced lymphangiogenesis. Mol Cancer 14: 35, 2015.

78. Redondo-Muñoz J, José Terol M, García-Marco JA and GarcíaPardo A: Matrix metalloproteinase-9 is up-regulated by CCL21/ CCR7 interaction via extracellular signal-regulated kinase-1/2 signaling and is involved in CCL21-driven B-cell chronic lymphocytic leukemia cell invasion and migration. Blood 111: 383-386, 2008.

79. Li F, Zou Z, Suo N, Zhang Z, Wan F, Zhong G, Qu Y, Ntaka KS and Tian H: CCL21/CCR7 axis activating chemotaxis accompanied with epithelial-mesenchymal transition in human breast carcinoma. Med Oncol 31: 180, 2014.

80. Xia X, Liu K, Zhang H and Shang Z: Correlation between CCR7 expression and lymph node metastatic potential of human tongue carcinoma. Oral Dis 21: 123-131, 2015.

81. Yang J, Wang S, Zhao G and Sun B: Effect of chemokine receptors CCR7 on disseminated behavior of human $\mathrm{T}$ cell lymphoma: clinical and experimental study. J Exp Clin Cancer Res 30: 51, 2011.

82. Calderaro J, Rebouissou S, de Koning L, Masmoudi A, Hérault A, Dubois T, Maille P, Soyeux P, Sibony M, de la Taille A, et al: PI3K/AKT pathway activation in bladder carcinogenesis. Int $\mathrm{J}$ Cancer 134: 1776-1784, 2014.

83. Islam SS, Mokhtari RB, Akbari P, Hatina J, Yeger $\mathrm{H}$ and Farhat WA: Simultaneous targeting of bladder tumor growth, Survival, and epithelial-to-mesenchymal transition with a novel therapeutic combination of acetazolamide (AZ) and sulforaphane (SFN). Target Oncol 11: 209-227, 2016. 